\title{
Microbial Diversity and Biosignatures: An Icy Moons Perspective
}

\author{
Jebbar Mohamed ${ }^{1,}{ }^{*}$, Hickman-Lewis Keyron ${ }^{2}$, Cavalazzi Barbara ${ }^{3}$, Taubner Ruth-Sophie ${ }^{4}$, \\ Rittmann Simon K.-M. R. ${ }^{5}$, Antunes Andre ${ }^{6}$
}

1 Univ. Brest, CNRS, Ifremer, Laboratoire de Microbiologie des Environnements Extrêmes, 29280, Plouzané, France

2 Dipartimento di Scienze Biologiche, Geologiche e Ambientali, Università di Bologna, Bologna, Italy

${ }^{3}$ Centre de Biophysique Moléculaire, CNRS, Rue Charles Sadron, 45071, Orléans, France

4 Department of Geology, University of Johannesburg, APK Campus, Johannesburg, South Africa

${ }^{5}$ Archaea Physiology \& Biotechnology Group, Archaea Biology and Ecogenomics Division, Department of Ecogenomics and Systems Biology, Universität Wien, Wien, Austria

${ }^{6}$ State Key Laboratory of Lunar and Planetary Sciences, Macau University of Science and Technology (MUST), Taipa, Macau SAR, China

*Corresponding author : Mohamed Jebbar, email address : mohamed.jebbar@univ-brest.fr

\begin{abstract}
:
The icy moons of the outer Solar System harbor potentially habitable environments for life, however, compared to the terrestrial biosphere, these environments are characterized by extremes in temperature, pressure, $\mathrm{pH}$, and other physico-chemical conditions. Therefore, the search for life on these icy worlds is anchored on the study of terrestrial extreme environments (termed "analogue sites"), which harbor microorganisms at the frontiers of polyextremophily. These so-called extremophiles have been found in areas previously considered sterile: hot springs, hydrothermal vents, acidic or alkaline lakes, hypersaline environments, deep sea sediments, glaciers, and arid areas, amongst others. Such model systems and communities in extreme terrestrial environments may provide important information relevant to the astrobiology of icy bodies, including the composition of potential biological communities and the identification of biosignatures that they may produce.
\end{abstract}

Extremophiles can use either sunlight (phototrophs) or chemical energy (chemotrophs) as energy sources, and different chemical compounds as electron donors or acceptors. Aerobic microorganisms use oxygen (O2) as a terminal electron acceptor, whereas anaerobic microorganisms may use nitrate (NO-3), sulfate (SO2-4), carbon dioxide (CO2), Fe(III), or other organic or inorganic molecules during respiration. The phylogenetic diversity of extremophiles is very high, leading to their broad dispersal across the phylogenetic tree of life together with a wide variety in metabolic diversity.

Some metabolisms are specific to archaea, for example, methanogenesis, an anaerobic respiration during which methane $(\mathrm{CH} 4)$ is produced. Also sulfur-reduction performed by some bacteria and archaea is considered as a primitive metabolism which is restricted to anoxic sulfur-rich habitats in nature. 
Methanogenesis and sulfur reduction are of specific interest for icy moon research as it might be one of the few known terrestrial metabolisms possible on these celestial bodies.

Therefore, the adaptation of these intriguing microorganisms to extreme conditions will be highlighted within this review.

Keywords : Extremophiles, Prokaryotes, Metabolism, Diversity, Adaptation, Space explorat 
Most definitions of a "living" process or system (Cleland and Chyba 2002) refer to three distinct properties: the ability to self-organize complex macromolecular structures, the ability to harness the energy necessary to maintain separate organization from the environment ("metabolism"), and an ability to replicate the self and to proliferate more or less identically. Thus, self-organization, metabolism and self-replication are the characteristic "cornerstones" of any living entity. This conceptual definition is the result of a long historical process, which has forced biologists of subsequent eras to redefine their understanding of what is, and is not, alive.

Regardless, a general and consensual definition of "living" is a matter of concern to many fields-physicists, chemists and astrobiologists-all of whom seek to recreate life-like behaviors, or to identify its signatures. A challenge is the continual confrontation only with terrestrial biology composed of a remarkably common base of molecular components (nucleic acids, proteins, lipids), each of which is dedicated to a main specific function: the conservation and handling of information for nucleic acids, structural organization and biochemical catalysis for proteins, and spatial delineation of compartments for lipids. On Earth, the co-occurrence of these building blocks indicates an affiliation with the "living" world.

The issue of the origin of life is usually addressed from two different perspectives: the first examines the conditions under which the basic building blocks and macromolecules significant for life may have emerged on the early Earth, the second explores the origin of functional subsystems (metabolism, replication) and basic structural organization (i.e., the cell) of what is recognized as "alive".

Experiments from the 1920s onward (Oparin 1924; Haldane 1929; Urey 1951; Miller 1953) led to the hypothesis of multiple "possible" scenarios of the origin of life (on Earth), often conflicting and irreconcilable, and typically almost mythological "stories" of physically and/or chemically possible processes, of which only small parts had an empirical basis. Despite their value in the inception of a debate on the origins of life, these hypotheses were often based on what we now know to be inaccurate or incomplete data (early Earth atmospheric composition, the genesis and dynamics of the Solar System, etc.). Early reports on the diversity of life (Woese 1979) also failed to consider the incredible metabolic sophistication that microbial life has shown in acquiring energy from its environment, even under the most inhospitable and extreme conditions. Clarification of the co-evolution of the 
biosphere and geosphere has led to an increasing recognition of the fact that the two are intimiately associated and likely constrained the development of the other (Lovelock and Margulis, ?lm74; Williams and Fraústo Da Silva 2003).

The Earth is generally thought of as a world inhabited by plants, animals and microorganisms able to grow under conditions compatible with life as it is found in most terrestrial and marine ecosystems (temperature: $10-40{ }^{\circ} \mathrm{C}, \mathrm{pH} \sim 7$, pressure: $1 \mathrm{~atm}$, water availability, minimal ionizing radiation level, etc.). Extremophiles have succeeded in inhabiting environmental niches with physicochemical parameters outside this comfort zone.

Extreme environments are characterized by environmental parameters at the boundaries of conditions that sustain and shape life in its various forms; whether terrestrial, oceanic, cryospheric or deep endolithic, they are widespread on our planet. Far from being marginal areas, they (especially the deep ocean and polar regions) represent, in terms of biomass volume, the most important part of the Earth biosphere.

In these extreme environments, dominated by prokaryotic microorganisms (Bacteria and Archaea), some organisms thrive under conditions that are at the limits of their physiological and energy potential, whereas others have highly adapted genetic features that result in acrucial requirement of such conditions. When classifying microorganisms as extremophiles, the concept of a "normal" environment is used as a reference. In assuming this anthropocentric view, it should not be forgotten that "extreme" environments, which today seem so hostile, appear to have predominated when the first life forms appeared on Earth. Nowadays, these environments are still colonized by highly diverse microbial communities.

Depending on the prevailing physico-chemical parameters of the environment, extremophiles can be subdivided into different categories: hyperthermophiles $\left(\mathrm{T}_{\mathrm{opt}} \geq 80^{\circ} \mathrm{C}\right)$ e.g. Methanopyrus kandleri, () the archaeon with the highest temperature life record); psychrophiles $\left(\mathrm{T}_{\mathrm{opt}} \leq 15^{\circ} \mathrm{C}\right.$ ) such as the bacterium Psychrobacter fulvigenes (Romanenko et al. 2009) capable of growing at temperatures as low as $-5^{\circ} \mathrm{C}$; acidophiles $\left(\mathrm{pH}_{\mathrm{opt}} \leq 3\right)$ including Picrophilus oshimae (Schleper et al. 1995), an archaeon that has shown optimal growth at $\mathrm{pH}=0.7$; alkaliphiles ( $\mathrm{pHopt} \geq 9$ ) such as Bacillus pseudofirmus (Nielson et al. ?ni95), capable of growing at $\mathrm{pH} \mathrm{11,} \mathrm{halophiles} \mathrm{such} \mathrm{as} \mathrm{the} \mathrm{archaeon} \mathrm{Halobacterium} \mathrm{salinarum}$ (Ventosa and Oren 1996), which can survive in the presence of $5.5 \mathrm{M} \mathrm{(32 \% )} \mathrm{NaCl} \mathrm{(its} \mathrm{sat-}$ uration limit); and piezophiles, e.g. Thermococcus piezophilus the archaeon that holds the record for withstanding the highest hydrostatic pressure (130 MPa, i.e. 1300 times atmospheric pressure) (Dalmasso et al. 2016).

Extremophiles expand our understanding of biodiversity on Earth and our knowledge of the limits of life. Deducing the mechanisms that enable extremophiles to persist under harsh conditions not only provides a thorough knowledge of the functioning of living cells but can also lead to interesting applications in biotechnology, particularly the economic utility of extremophiles. Understanding the uncommon properties of extremophiles has led to questions about their origin (have these organisms recently adapted to the extreme conditions of their environment or are they relics of organisms that existed on the Early Earth and that had to face even harsher environmental conditions?). Understanding the limits of life on Earth can provide hints of the diversity of potential extraterrestrial life (past or present). It is therefore not surprising that astrobiology studies the properties of life in Earth's extreme environments.

This review is dedicated to describing the state of the art and raising questions about taxonomic and metabolic diversity and the evolution of microorganisms (archaea and bacteria), notably extremophiles, and their biosignatures with an astrobiological perspective. 


\section{Extremophiles: Diversity, Adaptation and Biosignatures}

Over the past forty years, research has dramatically altered our understanding of the limits of life in terms of its physical and chemical constraints. Organisms, mainly prokaryotes, have been found to live optimally at very high or very low temperatures, in hyperacid or alkaline environments, or in salt-saturated environments, for example. Other organisms are able to live or survive under conditions of extreme stress, for instance a lack of water, the presence of high concentrations of heavy metals, or exposure to significant radiation doses or extreme pressures. In the following, we review and offer perspectives on extremotolerances to hypersaline and high hydrostatic pressure environments that are of particular relevance to the icy oceanic bodies of the outer Solar System.

\subsection{Hypersaline Biotopes}

Habitats with salinities higher than average seawater (i.e. 3.5\% total dissolved salts) are considered hypersaline. Many of these habitats result directly from the evaporation of sea water, and thus have similar relative proportions of ions; for example, they are dominated by sodium and chloride. Marine hypersaline environments are termed thalassohaline, in contrast to athalassohaline environments, which have non-marine ionic compositions and are associated with non-coastal water bodies (DasSarma and Arora 2001; Rodríguez-Valera 1988).

A profusion of hypersaline biotopes, distributed across the Earth, can be found in arid, coastal and even deep-sea settings (e.g. Antunes et al. 2011; DasSarma and Arora 2001; Oren 2002a, 2002b). In coastal regions, seawater often penetrates through seepage or narrow inlets creating small evaporation ponds. Well-known examples of such ponds are Solar Lake and Gavish Sabkha near the Red Sea coast, Guerrero Negro on the Baja California peninsula (Mexico), Lake Sivash near the Black Sea (Crimea), and Shark Bay in Western Australia. Such hypersaline evaporation ponds have also been found in Antarctica (e.g. Deep Lake, Organic Lake and Lake Suribati). Elevated salinities are usually found in natural inland hypersaline lakes such as the Dead Sea (Middle East) and the Great Salt Lake (USA), the two largest and best-studied such environments. A number of alkaline hypersaline soda brines also exist, including the Wadi Natrum lakes of Egypt, Lake Magadi in Kenya, the Great Basin lakes of the western United States (Mono Lake, Owens Lake, Searles Lake and Big Soda Lake), and several series throughout China and India.

The number of hypersaline sites is further increased by the numerous artificial solar salterns constructed for the production of sea salt, by subterranean brines and evaporite deposits and by the existence of several brine-filled deep-sea basins. Another type of hypersaline biotope is presented by the often-overlooked saline soils. These include desolate areas in such places as Death Valley (California, USA), Alicante (Spain), Iraq and even the Dry Valleys in Antarctica, amongst others (Ventosa et al. 1998).

Anoxic hypersaline basins, or deep-sea anoxic brines, are very special and rare environments in the oceans. They are formed as a result of tectonic activity and exposure of ancient salt deposits, existing under layers of sediments and originated from evaporated ancient seas (e.g. Antunes et al. 2011; Antunes 2017). The interaction of seawater with the underlying salt leads to the formation of brines which are 4 to 5 times more concentrated in salt than the surrounding seawater, creating highly saline "lakes" on the sea floor (Camerlenghi 1990). The presence of such basins often coincides with the presence of cold seep zones or, more rarely, hydrothermal vents, resulting in the release of methane, hydrogen sulphide and hydrocarbons. One of the characteristics of anoxic hypersaline basins is the 
presence of multiple gradients, particularly at the interface between seawater and the hypersaline zone (brine), including salinity, temperature, free $\mathrm{O}_{2}$, density and $\mathrm{pH}$ (Antunes et al. 2018). These physico-chemical gradients provide highly variable and specific environments of interest for the growth of microorganisms. In addition, the density gradient formed at the seawater/hypersaline zone interface acts as an organic and inorganic particle trap, providing the significant amount of nutrients necessary for cell growth (Daffonchio et al. 2006). It is possible to distinguish differences between the known brine lakes of different seas; in the Mediterranean Sea, concentrations of $\mathrm{Mg}^{2+}, \mathrm{SO}_{4}^{2-}$ and $\mathrm{K}^{+}$are high, whereas in the Red Sea, concentrations of $\mathrm{Ca}^{2+}$ and $\mathrm{Mn}^{2+}$ are higher. On the contrary, lower ionic concentrations, particularly $\mathrm{Mg}^{2+}$ and $\mathrm{K}^{+}$, exist in the Gulf of Mexico (Antunes et al. 2011).

The relevance of deep-sea brines in the context of the exploration of the oceans of the icy moons the outer solar system is particularly worth highlighting as they have been recently proposed as potential terrestrial analogues to conditions in such exooceans (Antunes et al., accepted).

\subsection{Biodiversity in Hypersaline Environments}

Despite being considered extreme, hypersaline environments host a diverse variety of organisms, including representatives from all three domains of life. In fact, microbial densities can be so high in these locations that the thriving communities of pigmented halophilic microorganisms (which includes a few bacteria but is composed mostly of halophilic archaea and/or the $\beta$-carotene-rich green alga Dunaliella) often give the water characteristic pinkish or even reddish hues. The inhabitants of saline environments range from higher organisms to unicellular eukaryotic microorganisms, and a heterogeneous group of prokaryotes, which constitute the predominant microflora (Rodríguez-Valera 1988; Ventosa and Nieto 1995).

\subsubsection{Eukarya in Saline Environments}

Within the domain Eukarya, halophiles are scarce, and mostly restricted to unicellular forms (Oren 2002b; Trüper and Galinski ?tg86). A variety of plants (e.g. Atriplex halimus) can survive in moderately high saline soils, although apparently no vertebrate has ever been reported at salinities higher than $1 \mathrm{M} \mathrm{NaCl}$ (DasSarma and Arora 2001; Ollivier et al. 1994). The most common multicellular eukaryotes in hypersaline environments are invertebrates, with reported species including rotifers, tubellarian worms, copepods, ostracods, and insects. Noteworthy among the insects are the well-known brine flies (Ephydra hians and E. gracilis) and brine shrimp (Artemia franciscana and A. salina), with the latter playing an important role in the nutrition of the pink flamingo and other birds (DasSarma and Arora 2001; Ventosa and Nieto 1995).

Dense populations of unicellular green algae can be observed at moderately high salinities, with most being moderate halophiles and only very few examples observed at higher salinity level (e.g. Dunaliella salina and Asteromonas gracilis). The several species of the genus Dunaliella are almost ubiquitous in hypersaline environments, being often the main or only primary producer and serving as main food source for brine shrimps and larvae of brine flies, while representatives of diatoms are also frequently found but rarely abundant (DasSarma and Arora 2001; Oren 2002a).

Other eukaryotic representatives include a large variety of protozoa (e.g. Porodon utahensis) as well as yeasts and other fungi (DasSarma and Arora 2001). These groups of organisms are very often overlooked when looking at the microbiology of high salinity 
environment but our knowledge about their diversity has been getting increased attention (excellently reviewed by e.g. Gunde-Cimerman et al. 2009; Hardy and Simpson ?hs17; Zajc et al. 2017).

\subsubsection{Archaea in Saline Environments}

Extreme halophiles are traditionally associated with the euryarchaeal class Halobacteria, which was recently reorganized (Gupta et al. 2015) and split into 3 different ordersHalobacteriales, Haloferacales, and Natrialbales - and is still undergoing taxonomic restructuring based on phylogenomic data (e.g. Gupta et al. 2016). As of September 2019, this family of aerobic euryarchaeotes currently comprises 259 species with validly published names, placed in 63 genera (Table 2). An interesting member of the Halobacteriaceae is the more recently isolated first representative of the square haloarchaea of Walsby, Haloquadratum walsbyi (Bolhuis et al. 2004; Burns et al. 2004). This intriguing group of microorganisms was first reported by Walsby (1980) but remained elusive despite numerous cultivations attempts and well-known widespread and abundant occurrence.

Extremely halophilic archaea are less common outside the Halobacteria but can also be found within some euryarchaeal genera namely within the class Methanomicrobia (e.g. Methanosalsum, Methanohalobium, Methanohalophilus, within the family Methanosarcinaceae and Methanocalculus, within an unassigned family of the order Methanomicrobiales, and the recently described genus Methanonatronarchaeum of the class Methanonatronarchaeia; Oren 2014; Ventosa et al. 2012; Sorokin et al. 2018). In addition to these, a few other methanogenic genera are also known to include moderately halophilic species (Ventosa et al. 1998). Aside from these methanogens, and the Halobacteria, no other archaeal halophiles have been identified outside the Euryarchaea.

\subsubsection{Bacteria in Saline Environments}

Overall, halophilic bacteria are a very diverse and heterogeneous group. Phylogenetically they are included in at least seven phyla: Actinobacteria, Bacteroidetes, Cyanobacteria, Firmicutes, Proteobacteria, Spirochaetes, and Thermotogae (Ventosa et al. 2012).

Compared to the Archaea, fewer examples of extreme halophily are currently known in Bacteria but their numbers have increased rapidly in the last few years. Some examples of this wide diversity include the actinomycete Actinopolyspora halophila, several gammaproteobacteria of the genus Halorhodospira, and Salinibacter ruber, which is a member of the Cytophaga-Flavobacterium-Bacteroides group (Antón et al. 2000, 2002; Kamekura 1998). Salinibacter is especially interesting due to its significant contribution to the biota of NaCl-saturated saltern crystallizer ponds. The surprisingly numerous similarities with the haloarchaea, specifically in osmotic adaptation strategy, point to a possible process of convergent evolution (Antón et al. 2002; Oren 2004).

Moderately halophilic bacteria, however, are much more diverse, being present in many of the major bacterial phylogenetic groups. The vast majority of the validly described moderately halophilic bacteria are members of the Proteobacteria, with the gamma-subgroup, namely the genera Salinivibrio, Marinobacter, and Arhodomonas, as well as members of the family Halomonadaceae, being especially preponderant. The Halomonadaceae includes some of the most versatile prokaryotes regarding their adaptability to a wide range of salinities (Oren 2000; Ventosa et al. 1998). Rhodospirillum salinarum, an anaerobic phototroph, and Desulfovibrio halophilus and Desulfohalobium retbaense, both anaerobic sulphate reducers, are further examples of organisms with wide ranges of salinity tolerances within 
the alpha- and delta-Proteobacteria, respectively (Galinski and Trüper 1994; Ollivier et al. 1994).

The Halanaerobiales, an order within the low $\mathrm{G}+\mathrm{C}$ branch of the Gram-positive bacteria includes the families Halobacteroidaceae and Halanaerobiaceae, other very important and numerous groups of moderately halophilic bacteria (Rainey et al. ?ra95). Further representatives are found in the low $\mathrm{G}+\mathrm{C}$ and high $\mathrm{G}+\mathrm{C}$ Gram-positive bacteria, the cyanobacterial branch, the Cytophaga-Flavobacterium-Bacteroides branch, and also within the spirochetes and the actinomycetes (Ventosa et al. 1998).

\subsubsection{Physiological Adaptations to High Salinity}

Life at high salinity is not without its burdens. Increased salinity leads to a decrease in water activity (i.e. the amount of water that is thermodynamically available) which, in accordance with the natural tendency of systems to attain and maintain equilibrium and the permeability of the cytoplasmic membrane to water, afflicts cells with osmotic stress (Brown 1990; Csonka 1989; Vreeland 1987). Indeed, an unadapted organism placed in a saline environment (i.e. hyperosmotic conditions) will rapidly lose water, leading to decreased cell volume and/or turgor pressure and ultimately affecting its metabolism and macromolecules (da Costa et al. 1998; Poolman and Glaasker 1998). Failure to adjust to these new conditions results in cessation of growth, possibly due to molecular crowding and a consequent reduction in diffusion rates of proteins and metabolites, which may eventually result in cellular death (Kunte et al. 2002). Evolution has provided life with two different approaches to deal with osmotic stress:

The salt-in-cytoplasm strategy. Using this strategy, the necessary thermodynamic adjustment of the cell is achieved through an increase in cytoplasmic salt concentration (normally through an increased intake of $\mathrm{K}^{+}$and $\mathrm{Cl}^{-}$). The resulting increase in intracellular ionic strength requires several changes in cellular function, most markedly at the level of the enzymatic machinery, resulting in a characteristic excess of acidic amino acids and small amounts of hydrophobic amino acids (da Costa et al. 1998; Oren 1999). The predominance of charged amino acids on the surface of enzymes and ribosomes stabilizes their hydration shells under high ionic conditions. Moreover, most of these enzymes are only functional at increased ionic levels (da Costa et al. 1998; Galinski and Trüper 1994). The permanent character of these cellular modifications restricts organisms that use this strategy to highly saline environments.

This salt-in-cytoplasm strategy was first discovered in aerobic, extremely halophilic archaea of the order Halobacteriales and is considered the typical archaeal strategy of osmoadaptation (Kunte et al. 2002). This strategy is also used by anaerobic halophilic bacteria of the order Halanaerobiales and the aerobic halophilic bacteria Salinibacter ruber (Oren 2000).

The organic-osmolyte strategy. This strategy relies on an increase in external salinity being counteracted by the accumulation (either by de novo synthesis or uptake from the environment) of uncharged, highly water-soluble, organic solutes (Kempf and Bremer 1998) (Fig. 1). These osmolytes do not disrupt metabolic processes and include sugars (e.g. trehalose), polyols (e.g. glycerol) and their derivatives, free amino acids (e.g. glutamate) and their derivatives, betaines, and ectoines (Csonka 1989; da Costa et al. 1998; DasSarma and Arora 2001; Galinski and Trüper 1994). This strategy allows organisms to keep their cytoplasm free of $\mathrm{NaCl}$, to a large extent, while avoiding the need for major changes in cellular machinery, thus providing a higher physiological flexibility. This explains the characteristically wide salt tolerance ranges associated with the use of this type of osmotic adaptation. 

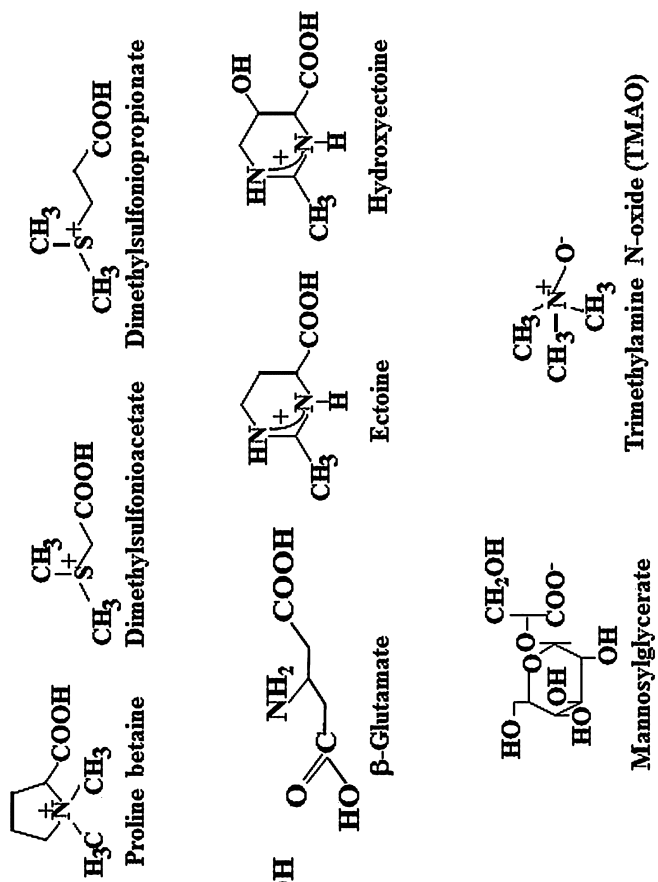

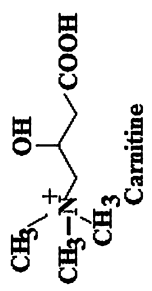
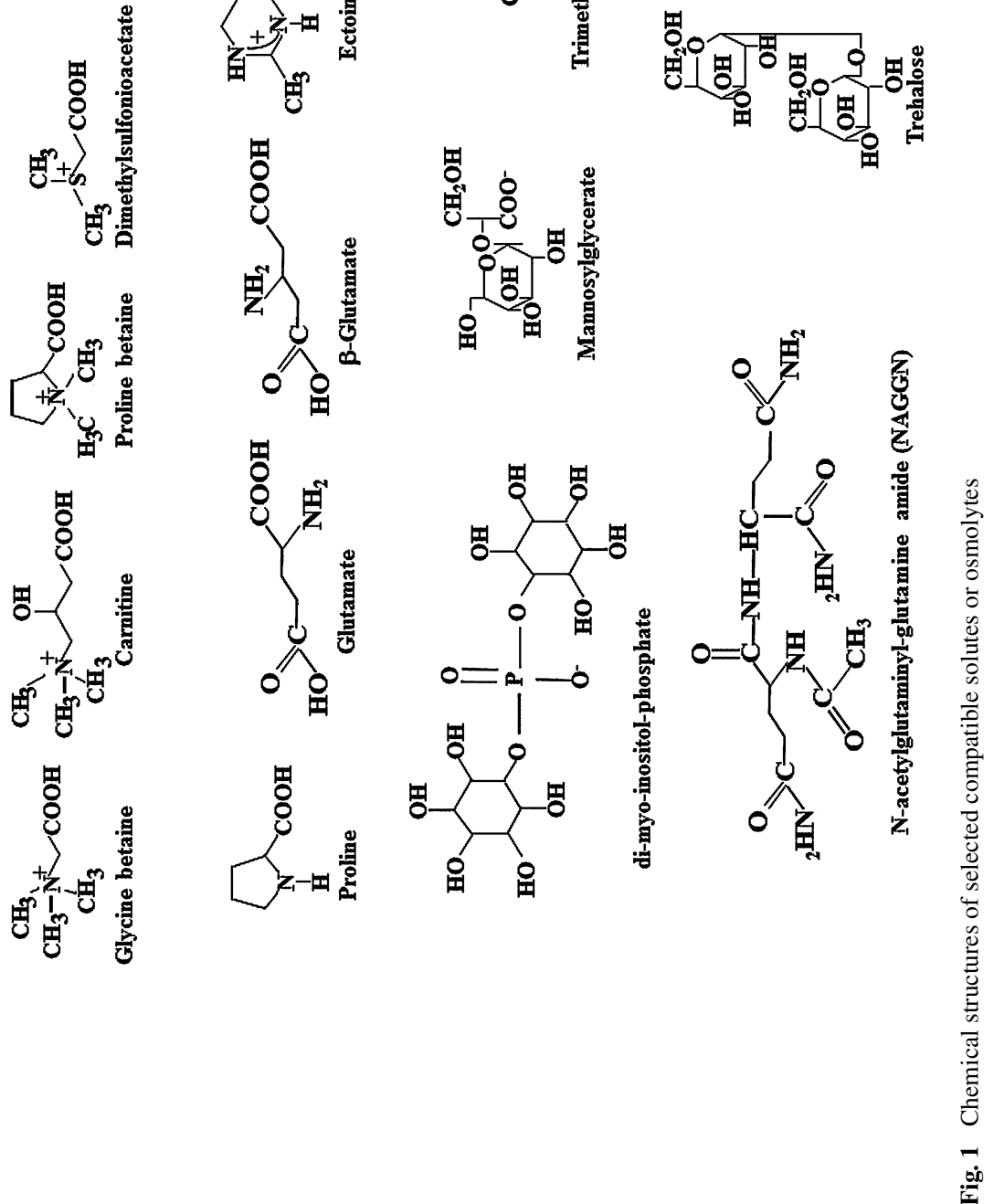
The organic-osmolyte strategy is widespread among Bacteria, Eukarya and some Archaea. Indeed, some methanogenic along with some haloalkaliphilic Archaea are known to use a combination of both strategies (Desmarais et al. 1997).

\subsection{High Hydrostatic Pressures Biotopes}

The Twentieth Century was marked by technological and scientific breakthroughs that have drastically modified the way we understand life on our planet. It was demonstrated that unicellular prokaryotic life forms are able to inhabit virtually any environment on Earth, and that they constitute life's largest diversity reservoir. The domain Archaea was created to accommodate newly isolated prokaryotic organisms with specific features that make them more similar to eukaryotes. Recent estimates also suggest that life dwells mostly underground (Reith 2011; Colwell and D'Hondt 2013; Colman et al. 2017) and that this deep biosphere, located in the continental subsurface and in the oceans below $1000 \mathrm{~m}$ in depth, could represent up to $70 \%$ of all cells on Earth, and up to 50\% of (Oger and Jebbar 2010) the primary production of biomass. Most of these biotopes are oligotrophic in nature and characterized by high hydrostatic pressures (HHP). Although the deep biosphere represents the largest ecosystem on Earth, however, it is still poorly characterized in terms of diversity and its mechanisms of adaptation to HHP.

Amongst deep-biosphere biotopes, hydrothermal vents may be the most intriguing. Discovered in 1979, they were shown, despite being hot oligotrophic and HHP environments, to harbor abundant primary productivity and diversity (Corliss et al. 1979). Primary production, in these environments, is based exclusively on the anaerobic chemical harvest of the energy of the geologically sourced fluids seeping through the ocean floor. Because of this, they are the only ecosystems on Earth not linked to photosynthesis, or photosynthesis-derived products such as $\mathrm{O}_{2}$. It has been postulated that deep-sea hydrothermal vent systems were the birth sites of life on Earth (e.g., Martin and Russell 2003; Russell et al. 2010) and this item is described below in more details in Part 4 of this review.

HHPs are ubiquitous in deep environments. Hydrostatic pressure increases with depth at an approximate rate of $10 \mathrm{MPa}(\sim 100$ atmospheres or 100 bar $)$ per $\mathrm{km}$ in the water column and $30 \mathrm{MPa}$ per $\mathrm{km}$ in the crust. The definition of the deep biosphere is conveniently and arbitrarily defined as water depths of $1000 \mathrm{~m}$ and more (Jannasch and Taylor 1984). Consequently, all environments above $10 \mathrm{MPa}$ qualify as high-pressure biotopes. HHP waters encompass $88 \%$ of the volume of the oceans-which have an average depth of $3800 \mathrm{~m}-$ and thus an average hydrostatic pressure of ca. $38 \mathrm{MPa}$, but reach $110 \mathrm{MPa}$ in the trenches. In contrast, the average geothermal gradient in the continental system is ca. $25^{\circ} \mathrm{C} \mathrm{km}^{-1}$ (Oger and Jebbar 2010). The current temperature limit for life, $122^{\circ} \mathrm{C}$ (Takai et al. 2008), would thus place the "deep" limit for the putative continental biosphere at ca. $5 \mathrm{~km}$ below ground on average, under maximal pressures of $150 \mathrm{MPa}$. Most of the Earth's prokaryotes live in these subsurface oceanic and terrestrial environments. From current knowledge of the deep-biosphere their cell number is estimated at $3.5 \times 10^{30}$ and ca. $2-6 \times 10^{29}$ respectively i.e. about 10 times that estimated for surface environments (Whitman et al. 1998; Magnabosco et al. 2018). Thus, even though the maximal productivity of the high-pressure continental or marine biosphere is orders of magnitude lower than that of the surface biotopes, due to their extremely large volume, these high-pressure biotopes contribute significantly to the production and recycling of organic carbon (Fig. 2) (Magnabosco et al. 2018). 
451

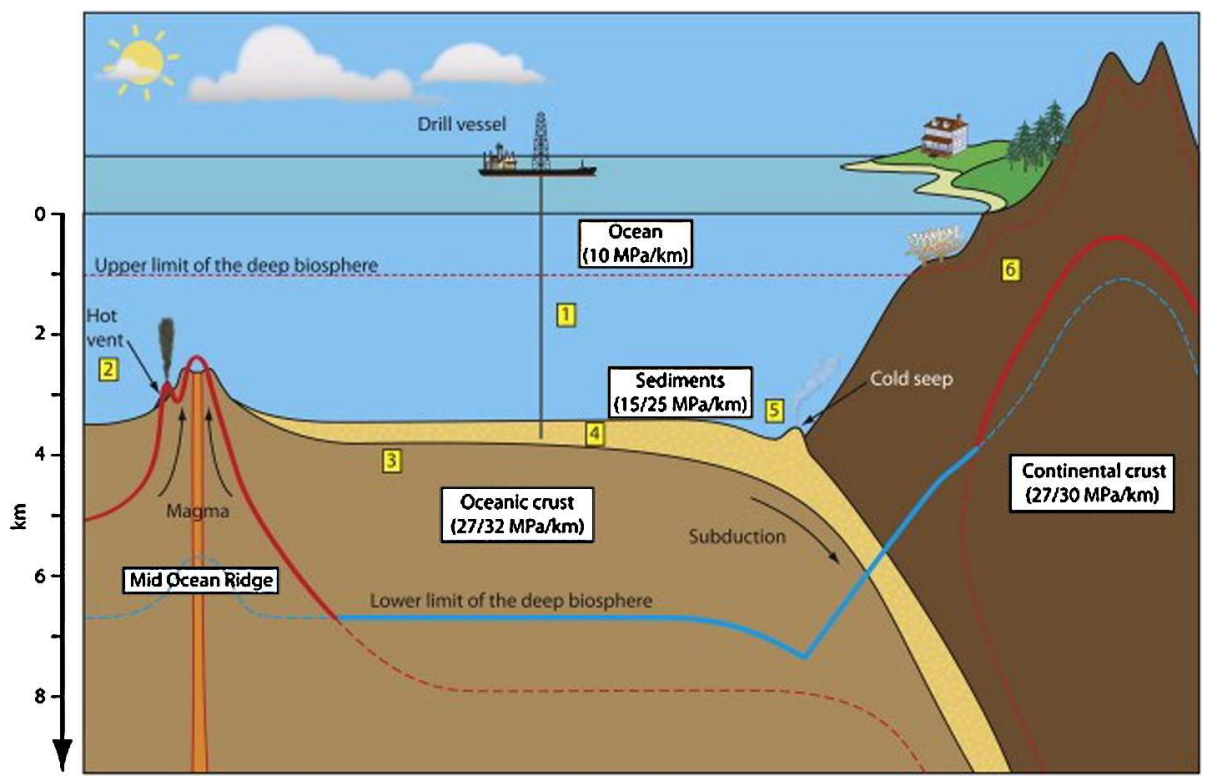

Fig. 2 Schematic transversal section of the Earth highlighting the numerous settings of the deep biosphere. 1: deep-sea; 2: deep-sea hydrothermal vents; 3 : deep oceanic crust; 4: sedimentary sub-seafloor; 5 : deep-sea cold seep; 6: continental deep biosphere. The red and blue lines represent the currently known temperature and pressure limits for life, respectively. Solid lines highlight the parameter which limits the depth of the deep biosphere. The upper dashed red line symbolizes the arbitrary $10 \mathrm{MPa}$ upper limit of the deep biosphere (Oger and Jebbar 2010)

\subsubsection{Physical Characteristics of High-Pressure Biotopes}

The deep ocean is characterized by HHP, darkness, a stable average temperature of ca. $2{ }^{\circ} \mathrm{C}$, low organic carbon and a relative constant oxygen concentration. It is estimated that, at present, ca. $1 \%$ of the carbon fixed by photosynthesis on the ocean surface eventually reaches the ocean floor, thus the major nutritional potential of the deep-sea is defined by a relatively low input of organic carbon (Oger and Jebbar 2010). As a corollary, adaptations to oligotrophy (life with limited access to nutrients) and psychrophily (optimal life at low temperature) are common in these environments. In contrast to the deep-sea biosphere, the deep-continental biosphere is considerably more diverse.

\subsubsection{Diversity of HHP-Adapted Microorganisms}

The field of piezomicrobiology has suffered largely from a requirement for expensive highpressure retention sample containment and culturing laboratory equipments. The first HHPadapted prokaryotes were bacteria isolated from deep-sea sediments by Zobell and Johnson (1949). The first obligate piezophiles, e.g. organisms that cannot develop at ambient pressure and temperature, were isolated in 1981 (Yayanos et al. 1981). The diversity of piezophiles in the deep-sea is largely dominated by five genera of psychrophilic, heterotrophic bacteria (Colwellia, Moritella, Shewanella, Psychromonas, and Photobacterium) from the gammaProteobacteria (Fig. 3). In contrast, the diversity of prokaryotes isolated from hydrothermal environments is dominated by archaeal and bacterial hyperthermophilic chemolithotrophs, i.e., those capable of gaining energy from the chemical transformation of dissolved minerals 
«SPAC 11214 layout: Small Condensed v.2.1 file: spac620.tex (ikurtinaitiene) class: spr-small-v1.4 v.2019/10/07 Prn:2019/12/05; 11:32 p. 11/42» doctopic: ReviewPaper numbering style: ContentOnly reference style: aps»

Microbial Diversity and Biosignatures: An Icy Moons Perspective

Page 11 of 42 _\#\#\#_

501

502

503

504

505

506

507

508

509

510

511

512

513

514

515

516

517

518

519

520

521

522

523

524

525

526

527

528

529

530

531

532

533

534

535

536

537

538

539

540

541

542

543

544

545

546

547

548

549

550

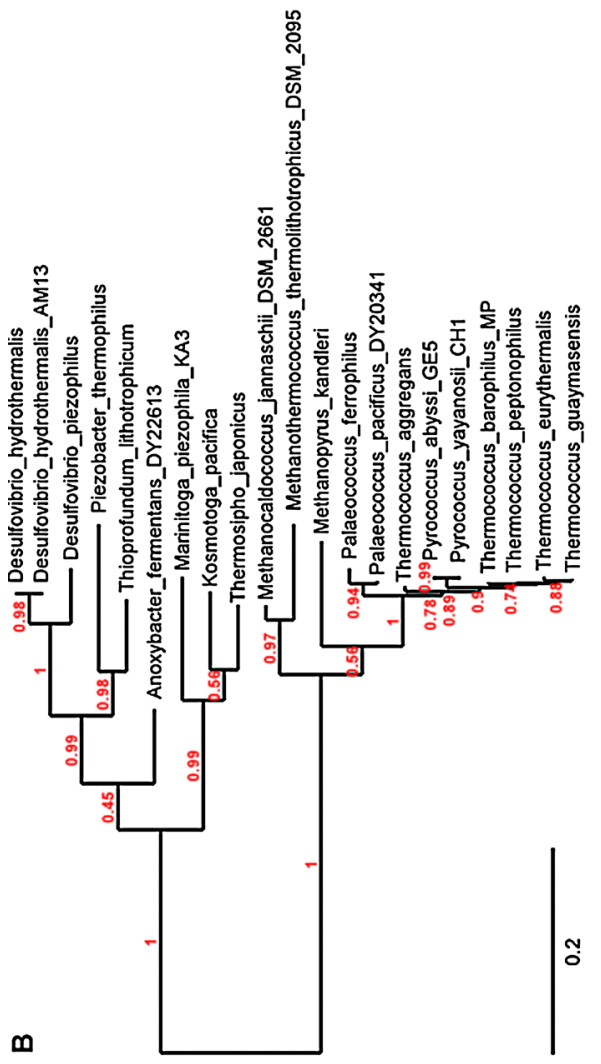

芯

을

สं

$\varpi$

产

范

坣

के

$\stackrel{乛}{\Xi}$

on

ज

चै

ปั

늘

अे क

웡

$\dot{s}$

ำ

흔

ㄴ.

ํㅡㄹ

응

린

ڤี

这

岤

তे

त)

范苟

के एँ

这

ชิ

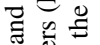

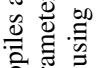

를

空志

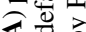

둥

㻤

产

.

可

궁

至

슬

लำ 
and able to fix dissolved carbonates into organic molecules (Jebbar et al. 2015). Discoveries of abundant life in diverse high-pressure environments, including the deep oceans, hydrothermal vents, and crustal rocks, supports the existence of an adaptation of life to HHP, and is consistent with the significance of HHP in the prebiotic synthesis of key biomolecules and the origin of life on Earth (Hazen et al. 2002).

\subsubsection{Effect of HHP on Biomolecules}

Pressure affects both chemical equilibrium and reaction rates, depending upon the reaction $(\Delta V)$ and activation $(\Delta V \neq)$ volumes involved. The behaviour of systems under high pressures is governed by Le Châtelier's principle, which states that the application of pressure shifts equilibrium toward the state that occupies the smallest volume. It accelerates a process in which the transition state has a smaller volume than that of the ground state, for example, if the volume of a protein is smaller in its unfolded form, this protein will be denatured by the application of HHP.

At HHP of greater than $400 \mathrm{MPa}$, most proteins tend to unfold (Aertsen et al. 2009). Exposure to mild HHP ( $200 \mathrm{MPa})$ often affects only the quaternary structure, leading to the dissociation of oligomeric proteins. As a consequence, HHP modulates the activity of enzymes. The enzymatic activities of proteins isolated from HHP-adapted organisms tend to be less affected by HHP than those of surface organisms (Aertsen et al. 2009), however, the true structure-function relationships underlying the pressure stability of proteins are still unknown.

\subsubsection{Effect of HHP on Biological Systems}

Biological membranes play a fundamental role in the adaptation of microbes to their environment. The membrane acts as a physical barrier to regulate influx and efflux activities, it plays a central role in energy storage and processing via ion gradients, and it provides a template for environmental sensing, multicomponent uptake and signaling pathways and motility. Thus, maintaining optimal membrane biological function is crucial for any organism. Temperature-, $\mathrm{pH}-$, salinity- or hydrostatic pressure-induced shortcomings in membrane organization are a serious threat to the cell. Archaeal and bacterial membranes have significant structural differences in spite of the fact that they perform identical functions. The mechanisms used by these membranes to cope with harsh conditions and shifting environments are quite similar. Bacterial polar lipids, with only a few rare exceptions, are based on straight chain hydrocarbons linked by ester bonds on the sn-1 and sn-2 positions of glycerol. Archaeal polar lipids are composed of isoprenoid hydrocarbon chains bound by ether bonds to the sn-2 and sn-3 positions of glycerol (Fig. 4). Polar headgroups consist of phosphodiester-linked polar groups or sugar moieties on the sn-1 (archaea) or sn-3 (bacteria) positions of the glycerol backbone (sn-glycerol-1-phosphate, or G-1-P, structure and sn-glycerol-3-phosphate, or G-3-P, structure).

Following the observation that the lipids in the membrane of E. coli cells grown under temperatures of $43{ }^{\circ} \mathrm{C}$ and $15^{\circ} \mathrm{C}$ were different (Marr and Ingraham 1962; Sinensky 1971), yet the corresponding membranes had similar physical characteristics at their respective growth temperatures, Sinensky simulated the homeoviscous adaptation basis (Sinensky 1974; Oger and Cario 2013). According to this approach, organisms adjust the lipid composition of their membrane to facilitate the preservation of the appropriate membrane fluidity in order to work optimally. This concept-in a broader sense-is understood to encompass adaptation to proton/water permeability and the dynamic character of plasmic membranes 
A

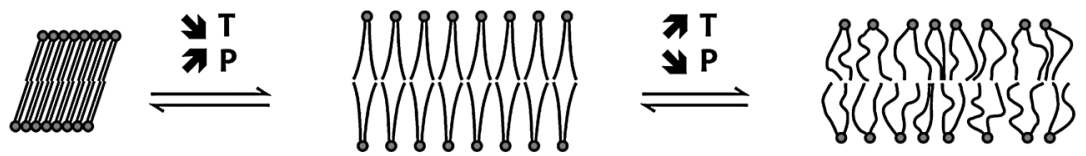

B

compact lipid layer

increased rigidity reduced lipid motion gel phase

reduced permeability

\section{Liquid crystalline state}

functional phase

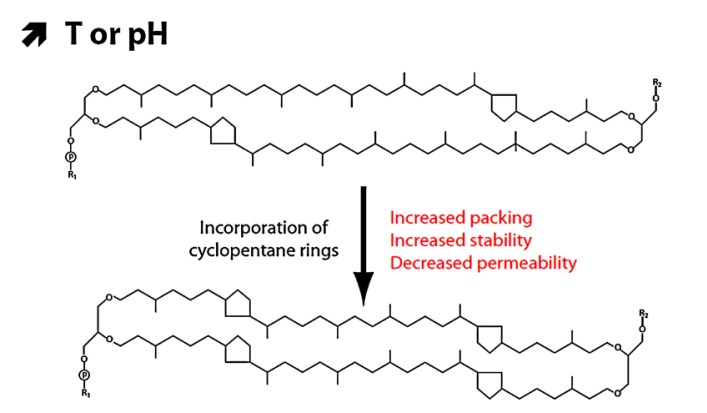

\section{T or $P$}

disordered membrane increased fluidity increased permeability increased lipid motion

\section{Fluid phase}

I

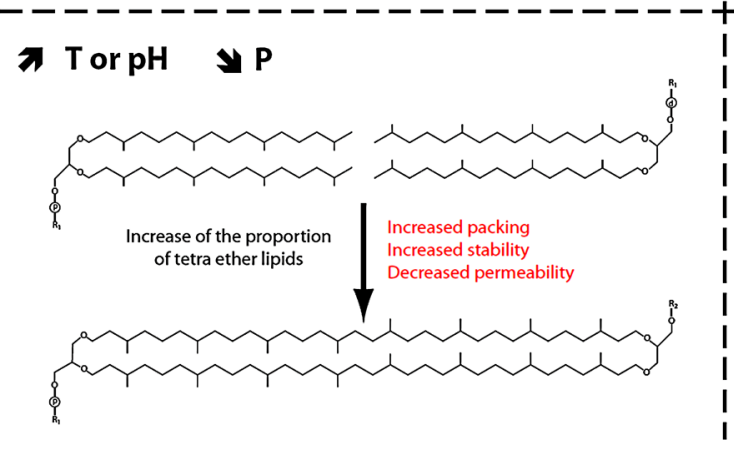

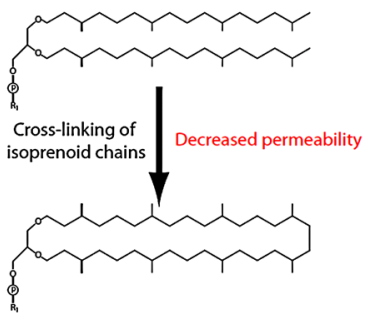

Fig. 4 Homeoviscous adaptation in Archaea. (A) In its functional state, the membrane is in a liquid crystalline state. Upon increasing temperature or decreasing hydrostatic pressure, lipid motion increases and the membrane enters the fluid phase. Conversely, when temperature drops or hydrostatic pressure increases, the lipid molecules pack more tightly and enter a gel phase. Membranes in both gel and fluid phases have impaired membrane function. (B) Known mechanisms of membrane lipid composition adaptation in Archaea (Oger and Cario 2013; Cario et al. ?ca15; Jebbar et al. 2015)

(Oger and Cario 2013). Homeoviscous adjustment should also be regarded as a manner of adapting the composition, and therefore the functionality, of the membrane to abrupt shifts in the environment, or to stresses, including those of temperature, salinity, osmotic stress, pressure and $\mathrm{pH}$. Under optimal physiological conditions, membranes are rather fluid and formed of disordered liquid crystalline phases. As temperature decreases or hydrostatic pressure increases, lipids in the membrane may undergo a transition from fluid to gel phase. If the 
«SPAC 11214 layout: Small Condensed v.2.1 file: spac620.tex (ikurtinaitiene) class: spr-small-v1.4 v.2019/10/07 Prn:2019/12/05; $11: 32$ p. 14/42» doctopic: ReviewPaper numbering style: ContentOnly reference style: aps»

temperature is higher or if the pressure is lower than the optimal physiological conditions, the movement rate of lipids in the membrane is greater, and this can affect the membrane's stability and its inherent permeability (Fig. 4). As one might expect, the disruption of the lipid phase state has a significant impact on the structure and function of the membrane (Lee 2003, 2004). The shift to the gel phase can lead to the aggregation of membrane proteins, which are excluded de facto from the gel phase areas, thereby limiting the diffusion and activity of proteins in the membrane and slowing down the flow of transported solutes, but enhancing the permeability of cations and water.

The adjustment of the characteristics of the bacterial membrane is made according to four main processes: (1) the change in acyl chain length, i.e., an increase in the length of the two-carbon chain causes an increase in the lipid phase transition temperature from $10^{\circ} \mathrm{C}$ to $20^{\circ} \mathrm{C}$, and decreases membrane permeability to protons and water (Winter 2002); (2) the build-up of unsaturated fatty acids, since the introduction of a single unsaturation can shift the fluid/gel transition from $10^{\circ} \mathrm{C}$ to $20^{\circ} \mathrm{C}$ (Russell and Nichols 1999; Winter 2002); (3) the accumulation of specific polar groups such as phosphatidylcholine (PC) or phosphatidylglycerol (PG) instead of phosphatidylethanolamine (PE), indeed, the presence of $\mathrm{PC}$ as a polar head group results in a significant change in the fluid/gel transition temperature (Yano et al. 1998; Winter 2002; Mangelsdorf et al. 2005; Winter and Jeworrek 2009), partially due to the diminished hydration and stearic volume of ethanolamine compared to choline, and partially to the capacity of PE and the failure of the PC groups to form hydrogen bonds; and (4) the buildup of branched-chain fatty acids.

Archaeal lipid membranes usually have a considerably lower phase transition temperature than bacterial acyl fatty ester lipids (Yamauchi et al. 1993). The adaptation of the archaeal membrane to extreme environments may be attributed in part to the specific structure of its lipids. Although membranes consisting of fatty acyl ester lipids are in the gel phase or liquid crystal phase according to their fatty acid composition, it is presumed that Archaeal polar lipid membranes of archaeol and caldarchaeol are in the liquid crystal phase over a wide temperature range of $0-100^{\circ} \mathrm{C}$ (Stewart et al. 1990; Dannenmuller et al. 2000).

The adaptability of the archaeal membrane is very similar in its physics to that of the bacterial membrane, albeit using slightly different mechanisms to attain the same effects. There exist several different routes, as follows. (1) The incorporation of cyclopentane rings along the isoprenoid chain as a function of fluctuating temperature (De Rosa et al. 1980a, 1980b; Ernst et al. 1998; Uda et al. 2001, 2004) or pH (Shimada et al. 2008) increases the packing efficiency of the membrane lipids (Gliozzi et al. 1983), which increases membrane stability as a function of increasing temperature or salinity and decreasing pressure or $\mathrm{pH}$, and consequently lowers membrane permeability (Chong et al. 2012). (2) The regulation of the tetraether-to-diether lipid ratio (Sprott et al. 1991; Lai et al. 2008; Matsuno et al. 2009; Baumann et al. 2018; Taubner et al. under review; Taubner et al. (under review)), since increasing tetraether lipids will stabilize membranes by forming monolayer-type membranes or domains in the membrane, and consequently helping to regulate the flux of solutes and protons across the membrane. (3) The crosslinking of the two acyl-chains of the lipids yields macrocyclic archaeol or caldarchaeol derivatives by a covalent bond between the isoprenoid chains, which also reduces molecular motion to create a more closely packed structure and increases membrane stability, creating an efficient barrier against water, proton and solute leakage (Dannenmuller et al. 2000; Mathai et al. 2001). (4) The increase in unsaturation along the isoprenoid chains of the lipids as a function of temperature (Nichols et al. 2004) or salinity (Dawson et al. ?da12); although this has, to date only been described in the psychrophilic methanogen 
«SPAC 11214 layout: Small Condensed v.2.1 file: spac620.tex (ikurtinaitiene) class: spr-small-v1.4 v.2019/10/07 Prn:2019/12/05; 11:32 p. 15/42» doctopic: ReviewPaper numbering style: ContentOnly reference style: aps»

Microbial Diversity and Biosignatures: An Icy Moons Perspective

Page 15 of 42

_\#\#\#\#-

Methanococcoides burtonii (Franzmann et al. 1992; Nichols et al. 2004), unsaturated lipids have been characterized in several species of hyperthermophiles (Hafenbradl et al. 1993; Gonthier et al. 2001), which might indicate the occurrence of a similar adaptive strategy in deep-sea hydrothermal vent organisms.

The adaptation of bacterial and archaeal membranes to harsh environments is clearly visible in the most common lipids, however, responding to variations in environmental stressors might involve only a fraction of the adaptive traits mentioned above. Indeed, in order to be effective, the membrane composition adaptation response needs to be very rapid. The routes described require different timeframes, thus certain adaptive mechanisms will prevail over others. For example, the increasing unsaturation of membrane lipids will decrease the gel/fluid transition temperature to the same extent as the shortening of an acyl chain or the substitution of a phosphatidylcholine by a phosphatidylethanolamine polar head, but will be quicker because it is performed inside the cytoplasmic membrane on existing lipids by a membrane protein (Kasai et al. 1976; Cybulski et al. 2002; Aguilar and de Mendoza 2006; Beranova et al. 2008), whereas the other actions would require de novo lipid synthesis.

\subsubsection{Adaptations to HHP in Piezophiles}

DeLong and Yayanos (1985) showed that deep-sea organisms harbor an unusually high proportion of mono- and poly-unsaturated fatty acids. This leads to highly disordered phospholipid bilayers that are less permeable to water molecules and are proposed to maintain the plasma membrane in a functional fluid state despite the rigidification effect of pressure. The genes responsible for the synthesis of these unsaturated lipids have been shown to be upregulated by HHP in the moderate piezophile Photobacterium profundum strain SS9, and are induced by HHP as part of the HHP-induced stress response in yeast (Allen et al. 1999; Abe 2015). These results have led workers to propose that adaptation to HHP involves the expression of HP-specific genes. This view is supported by genome-wide comparisons of gene expression in piezophile and piezosensitive strains of the Photobacterium complex (Campanaro et al. 2005).

In $P$. profundum SS9, transporters are mainly up-regulated at sub-optimal growth pressure, e.g. $0.1 \mathrm{MPa}$ in comparison to the pressure optimum of $28 \mathrm{MPa}$. Bartlett and colleagues (Lauro et al. 2008) speculated that SS9 transporters evolved a novel protein structure to adapt to elevated pressures, and that their up-regulation at $0.1 \mathrm{MPa}$ could compensate for a reduction of functionality at lower pressures. Kasahara et al. (2009) first demonstrated a weak HHP adaptation in the 3-isopropylmalate dehydrogenase of piezophilic Shewanella strains. Thus, adaptation to HHP may result from an evolution of proteins towards an optimal activity under HHP. The observation of the growth of T. piezophilus at $130 \mathrm{MPa}$, and that of the dissociation of ribosomes in E. coli at ca. $30 \mathrm{MPa}$, clearly supports the necessity for HHP-adapted ribosomes in the piezophilic strain.

Piezophilic Shewanella express a specific cytochrome protein complex under HHP (Tamegai et al. 1997). The importance of specific piezo-adaptation in the respiratory chain is further suggested by the presence of three complete sets of cbb3 cytochrome oxidase genes in the $P$. profundum SS9 genome (Vezzi et al. 2005). A large-scale transposon mutagenesis of $P$. profundum revealed several HHP-specific loci, most of which are involved in chromosomal partitioning and ribosomal function (Lauro et al. 2008). Therefore, adaptation to HHP may require specific genes.

In the deepest parts of the oceans and, if present, on ocean worlds, hydrothermal vent ecosystems are characterized by large fluctuations in salinity and temperature, from 0.1 to twice the salinity of seawater and from fluid temperatures as high as $350{ }^{\circ} \mathrm{C}$ at the heart of the 
«SPAC 11214 layout: Small Condensed v.2.1 file: spac620.tex (ikurtinaitiene) class: spr-small-v1.4 v.2019/10/07 Prn:2019/12/05; $11: 32$ p. 16/42» doctopic: ReviewPaper numbering style: ContentOnly reference style: aps»

vent, to $2{ }^{\circ} \mathrm{C}$, the average temperature of the surrounding deep ocean waters. Hydrothermal vent environments in the deep sea are also subject to extremely high hydrostatic pressures up to $50 \mathrm{MPa}$, i.e., 500 times the atmospheric pressure, based on values measured at the deepest known hydrothermal vent field in the Cayman Trough of the Caribbean Sea (Dalmasso et al. 2016).

Deep sea hydrothermal vents are among the ecosystems on Earth where polyextremophilic conditions or multi-stress situations are encountered by living organisms, such as high or low temperature, high salinity, high hydrostatic pressure and nutrient starvation within the same environment. Organisms, whether eukaryotes or prokaryotes, thriving in these areas have evolved mechanisms to adapt to these harsh conditions. It is known that an increase in hydrostatic pressure affects many cell functions involving macromolecules, including growth, cell division and protein synthesis (Bartlett 2002). High salinity and high and low temperatures have in common that they may trigger a cell dehydration effect and the loss of internal water, thus compromising the ability of the cell to survive. An increase in hydrostatic pressure does not result in changes in the pressure differential across the cell membrane, whereas increased salinity may trigger an increase in osmotic pressure outside the cell that provokes a change in turgor pressure. To maintain the appropriate cell turgor and restore the cell volume, organisms accumulate low-molecular-weight osmolytes that are mainly organic solutes. These organic solutes are also accumulated by many organisms in cold and heat stresses, and possibly under high hydrostatic pressure (Martin et al. 2002; Yancey 2005). The solutes are amino acids and derivatives, polyols, sugars and derivatives, methylamines, and methylsulfonium compounds (Fig. 1). Organic osmolytes fall into several chemical categories: amino acids (glycine, alanine, proline, $\alpha$-glutamate, $\beta$-glutamate, and $\mathrm{N}$-acetyl- $\beta$-lysine), and derivative $\mathrm{N}$-methyl-substituted amino acids (e.g., glycine betaine, homobetaine, carnitine, proline betaine, trimethylamine oxide), ectoine and hydroxyectoine, methylsulfonium solutes (dimethylsulfoniopropionate and dimethylsulfonioacetate), and small carbohydrates including monosaccharides (glucose), disaccharides (trehalose, sucrose, mannosucrose), sugar derivatives (glucosyglycerol, mannosylglycerate, glucosylglycerate), polyols (glycerol, inositol, sorbitol), and cyclitols (di-myoinositol-phosphate) (Empadinhas and da Costa 2006; Neves et al. 2005; Wood et al. 2001; Jebbar et al. 1992; Essendoubi et al. 2007; Yancey 2005; Kempf and Bremer 1998). Some solutes are widespread, for example glycine betaine, which is found in all domains of the tree of life, and carbohydrate osmolytes that occur in bacteria, archaea, fungi, algae, plants, mammalian kidneys and possibly deep-sea invertebrates. Other solutes are restricted to a small number of organisms, for example those thriving in hot environments (Empadinhas and da Costa 2006). Most organic osmolytes are neutral (either zwitterionic or lacking charges) at optimal physiological $\mathrm{pH}$, although some (i.e. mannosylglycerate and di-myoinositol-phosphate in hyperthermophilic prokaryotes) are negatively charged and must be paired with potassium to achieve neutrality.

These solutes are often called "compatible solutes", a term that refers to compounds that can accumulate at very high levels without perturbing cell metabolism or enzyme activity (Brown 1976). Many such solutes have protective properties, such as cell metabolic protection, and serve as antioxidants that scavenge free radicals and reactive oxygen species generated under stress treatments (Cushman 2001; Sunda et al. 2002; Yancey 2005). They can also stabilize macromolecular structures (proteins, membranes) only when stresses such as high salinity, high temperature, freezing and high hydrostatic pressure are present and directly destabilize cell components (Singer and Lindquist ?s198; Story and Story ?ss96; Rudolph and Crowe ?rc85; Santos and da Costa ?sc02; Kelly and Yancey 1999).

In many bacteria and archaea, it has been demonstrated that a number of compatible solutes are accumulated by the cell in response not only to salt stress but also as a means 
to counteract the destabilizing effects of heat and chill stresses on cell macromolecules (Kuhlmann et al. 2008; Empadinhas and da Costa 2006; Holtmann and Bremer 2004). Despite this, the compatible solute counteraction of the destabilizing effect of high hydrostatic pressure on macromolecules is not obvious and poorly demonstrated, particularly in prokaryotic cells. Yancey and coworkers have shown that the organic osmolyte trimethylamine oxide (TMAO) occurs at high levels in many deep-sea animals in comparison to related shallow-water species (Gillett et al. 1997, Kelly and Yancey 1999). Since hydrostatic pressure is the only physico-chemical parameter that is linear with depth, these authors suggested that TMAO might counteract the effects of high hydrostatic pressure. In the deep-sea bacterium $P$. profundum strain SS9, cells accumulate mainly glutamate and glycine betaine at atmospheric pressure $(0.1 \mathrm{MPa})$, whereas at optimal growth pressure $(28 \mathrm{MPa})$, cells preferentially increase intracellular concentrations of $\beta$-hydroxybutyrate and $\beta$-hydroxybutyrate oligomers termed "piezolytes" for solutes that are accumulated at high hydrostatic pressures (Martin et al. 2002). In addition, another study on marine bacteria has shown that adaptation to high salinity synergistically enhances cell survival at high hydrostatic pressures, which suggests the involvement of osmolytes in counteracting both stresses in these prokaryotes (Kaye and Baross ?kb04).

In hyperthermophilic piezophiles, it is evidenced that adaptation to HHP involves a global change in the expression of genes in some metabolic pathways (amino acid biosynthesis, hydrogen metabolism), rather than the expression of a stress response per se (Vannier et al. 2015). In Thermococcus barophilus, for example, adaptation to HHP involves osmolyte accumulation to maintain proper protein folding and activity (Cario et al. 2016). Mannosylglycerate $(\mathrm{MG})$ is primarily accumulated as a compatible solute in response to salinity stress, but in contrast to other Thermococcales, MG also accumulates in response to thermal stresses, and its accumulation peaked in the case of combined stresses. The accumulation of MG has been found to drastically increase under sub-optimal hydrostatic pressure conditions, demonstrating that low pressures are perceived as a form of stress in this piezophile, and that the proteome of $T$. barophilus is sensitive to low-pressures. MG accumulation is strongly reduced under supra-optimal pressure conditions, clearly demonstrating the structural adaptation of this proteome to high hydrostatic pressure. There is direct and indirect evidence for the structural adaptation of the proteome to HHP, although the specific signature of this adaptation at the genome level remains elusive.

This section provided an in-depth overview of the biodiversity of micro-organisms in extreme hypersaline environments and also where high hydrostatic pressure prevails. Molecular signatures and cellular and physiological responses to extreme salinity and high hydrostatic pressures were also examined. Among the microorganisms associated with these extreme environments described above are the methanogenic archaea that have successfully colonized all of the earth's ecosystems. Methanogenesis and methanogens are described in more detail in the following paragraph.

\section{Methanogens as Model Organisms for Icy Moon Related Cultivation: Adaptation to Extreme Conditions}

McKay et al. (2008, 2012) determined that only three microbial ecosystems on Earth could serve as analogues for a potential ecosystem on an icy moon. These ecosystems do not rely on photosynthesis, on any by-product of photosynthetic metabolism, nor are they dependent on $\mathrm{O}_{2}$. One of these ecosystems is based on sulfur-reducing bacteria, and the other two are based on methanogenic archaea (methanogens). In the following section, we will focus on 
methanogens and their adaption to extreme conditions. A more detailed review about that topic can be found in Taubner et al. (2015).

Besides Earth, methane $\left(\mathrm{CH}_{4}\right)$ has been detected on every planet of the Solar System, on the dwarf planets Pluto, Makemake, and Eris (Formisano et al. 2004, Mumma et al. 2009, Webster et al. 2015), and on the icy moons Titan (Niemann et al. 2005) and Enceladus (Waite et al. 2009, 2014, 2017). Most of the $\mathrm{CH}_{4}$ found on Earth is of biogenic origin (Liu et al. 2008). Methanogens are the overwhelmingly dominant producers of $\mathrm{CH}_{4}$ as metabolic end products of their carbon- and energy-yielding reactions (Thauer et al. 2008; Liu et al. 2008; Taubner et al. 2015; Rittmann et al. 2015), however, some (aerobic) marine microorganisms were also shown to produce $\mathrm{CH}_{4}$ from methylphosphonic acid (Karl et al. 2008; Metcalf et al. 2012; Carini et al. 2014). Methanogens are a phylogenetically and metabolically diverse group of prokaryotic organisms from the domain Archaea. Within the domain Archaea, methanogens belong exclusively to the phylum Euryarchaeota. All characterized methanogens are known to be obligate anaerobic chemolithoheterotrophs or chemolithoautotrophs. Moreover, methanogens might resemble amongst the oldest life forms that emerged on Earth (Grassineau et al. ?gr06; Ueno et al. 2006; Martin et al. 2008), but this is still under discussion (Brochier-Armanet et al. 2011; Blank 2009). Methanogens are used as astrobiological study objects because of both their metabolic versatility and ability to withstand extreme environmental conditions (Cavicchioli 2006; Huber et al. 1989; Taubner et al. 2018); they are further characterized by a variety of unusual morphological and ecophysiological features. In this subsection, we review and discuss methanogens with respect to temperature, pressure, $\mathrm{pH}$ and osmolarity, and highlight recent studies performed with methanogens in an astrobiological context.

\subsection{Adaptions to Temperature}

Individual methanogenic strains are viable within a temperature window for growth of approximately $45^{\circ} \mathrm{C}$, however, the biochemical pathways of methanogenesis per se are not restricted to a certain temperature, but are generally functional at temperatures from below $0{ }^{\circ} \mathrm{C}$ (Cavicchioli 2006) up to $122^{\circ} \mathrm{C}$. This allows individual strains of methanogens to grow from psychrophilic to hyperthermophilic growth conditions (Nakamura et al. ?na13; Ma et al. 2006; Lü and Lu 2012; L'Haridon et al. 2003; Jones et al. 1983a; Jiang et al. 2005; Jeanthon et al. 1998; Jeanthon et al. 1999; Cheng et al. 2007; Parshina et al. 2014; von Klein et al. 2002; Franzmann et al. 1997; Wagner et al. 2013; Schirmack et al. 2014; Takai et al. 2008). Metabolic reactions occurring at the highest temperatures were observed for M. kandleri strain 116 when grown at $122^{\circ} \mathrm{C}$ (Takai et al. 2008).

Bodies of the outer Solar System, which could possibly support methanogenic life, fall within the temperature range of psychrophilic methanogens. Recent results advocate the possibility that hydrothermal vents might exist on icy moons, such as Enceladus (Hsu et al. 2015) or Europa (e.g., Zolotov and Kargel 2009), which would widen the growth temperature range for methanogens in the subsurface water reservoirs of these bodies. However, as these potential warm to hot spots at the bottom of the subsurface oceans are most likely locally restricted, we will focus on psychrophilic methanogens in the following.

To distinguish different levels of psychrophily, psychrophilic methanogenic strains were classified according to their temperature niche adaptation, which can be narrow or wide (Cavicchioli 2006; Dong and Chen 2012), respectively denoted as "stenopsychrophile" and "eurypsychrophile" organisms (Cavicchioli 2006; Siddiqui et al. 2006; Feller and Gerday 2003). Stenopsychrophiles are considered true psychrophiles and are only able to grow within a narrow temperature range. Compared to stenopsychrophiles, eurypsychrophiles can tolerate a larger temperature interval, tolerate a higher mean optimum 
«SPAC 11214 layout: Small Condensed v.2.1 file: spac620.tex (ikurtinaitiene) class: spr-small-v1.4 v.2019/10/07 Prn:2019/12/05; 11:32 p. 19/42» doctopic: ReviewPaper numbering style: ContentOnly reference style: aps»

Microbial Diversity and Biosignatures: An Icy Moons Perspective

Page 19 of 42

-\#\#\#\#_

901

902

903

904

905

906

907

908

909

910

911

912

913

914

915

916

917

918

919

920

921

922

923

924

925

926

927

928

929

930

931

932

933

934

935

936

937

938

939

940

941

942

943

944

945

946

947

948

949

950

Table 1 Summary of presently known psychrophilic strains and their main temperature and $\mathrm{pH}$ features

\begin{tabular}{|c|c|c|c|c|c|c|c|}
\hline \multirow[t]{2}{*}{ Strain } & \multicolumn{3}{|c|}{$\mathrm{T}\left[{ }^{\circ} \mathrm{C}\right]$} & \multicolumn{3}{|l|}{$\mathrm{pH}$} & \multirow[t]{2}{*}{ Ref. } \\
\hline & $\min$ & opt & $\overline{\max }$ & $\min$ & opt & $\overline{\max }$ & \\
\hline Methanospirillum psychrodurum & 4 & 25 & 32 & 6.5 & 7 & 8 & Zhou et al. (2014) \\
\hline Methanosarcina baltica & 3 & 21 & 28 & 6.3 & 7.2 & 7.5 & von Klein et al. (2002) \\
\hline Methanosarcina lacustris & 1 & 25 & 35 & 4.5 & 7 & 8.5 & Simankova et al. (2001) \\
\hline Methanolobus psychrophilus & 0 & 18 & 25 & 6 & $7-7.2$ & 8 & Zhang et al. (2008) \\
\hline Methanogenium marinum & 5 & 25 & 25 & 5.5 & $6-6.6$ & 7.7 & Chong et al. (2002) \\
\hline Methanogenium frigidum & 0 & 15 & 17 & 6.3 & $7.5-7.9$ & 8 & Franzmann et al. (1997) \\
\hline Methanohalobium evestigatum & 50 & n.a. & n.a. & n.a. & 7.4 & n.a. & Zhilina and Zavarzin (1987) \\
\hline Methanogenium cariaci & 15 & $20-25$ & 35 & 6 & $6.8-7.2$ & 7.5 & Romesser et al. (1979) \\
\hline Methanogenium boonei & 5 & 19.4 & 25.6 & 6.4 & n.a. & 7.8 & Brauer et al. (?br11) \\
\hline Methanoculleus marisnigri & 15 & $20-25$ & 48 & 6 & $6.2-6.6$ & 7.6 & Maestrojuán et al. (1990) \\
\hline Methanoculleus chikugoensis & 15 & 25 & 40 & 6.7 & $6.7-7.2$ & 8 & Dianou et al. (2001) \\
\hline Methanococcoides alaskense & 2.3 & 23.6 & 28.4 & 6.3 & n.a. & 7.5 & Singh et al. (2005) \\
\hline Methanococcoides burtonii & 1.7 & 23.4 & 29.5 & 6.8 & n.a. & 8.2 & Franzmann et al. (1992) \\
\hline Methanospirillum stamsii & 5 & $20-30$ & 37 & 6 & $7.0-7.5$ & 10 & Parshina et al. (2014) \\
\hline Methanosarcina soligelidi & 0 & 28 & 54 & 4.8 & 7.8 & 9.9 & Wagner et al. (2013) \\
\hline
\end{tabular}

growth temperature, and can (sometimes) be cultivated when exposed to elevated temperatures. Psychrophilic methanogens have been used in many research ventures, as they are important organisms in cold habitats on Earth (Cavicchioli 2006; Dong and Chen 2012). A list of psychrophilic methanogenic strains and their respective temperature niche can be found in Table 1.

The temperature adaptation mechanisms of methanogens were identified at different levels. At the protein level, cold adaptation mechanisms were examined in Methanococcoides burtonii. Here, the archaeal elongation factor 2 (EF2) proteins were found to be active at low growth temperatures but unstable at high growth temperatures (Siddiqui et al. 2002; Thomas and Cavicchioli 2000; Thomas et al. 2001). Moreover, proteins interacting with EF2 of $M$. burtonii, but also compatible solutes, are involved in activating as well as stabilizing protein machinery under low growth temperatures (Thomas et al. 2001). Another study showed that in $M$. burtonii, a putative DEAD box RNA helicase gene (deaD) was abundantly expressed at $4{ }^{\circ} \mathrm{C}$ (Lim et al. 2000). Additional characteristics for cold adaptation in methanogens include the increased presence of dihydrouridine in tRNAs of M. burtonii compared to the presence of dihydrouridine in other archaeal strains (Noon et al. ?no03). Unlike adaptations to cold in thermophiles, $M$. burtonii did not show decreased modification of its tRNAs, but exhibited few modifications (comparable to bacteria), in particular dihydrouridine incorporation into tRNA.

A genome comparison of the psychrophilic methanogens, $M$. burtonii and Methanogenium frigidum was performed to identify characteristics which distinguish cold adaption mechanisms in these organisms from other archaea. Predicted and modelled proteins from $M$. burtonii and $M$. frigidum comprise a higher quantity of non-charged polar amino acids present in the solvent-accessible area of proteins. Specifically, glutamine and threonine were detected in higher abundance. Moreover, a lower content of hydrophobic amino acids, in particular leucine, were noted. Finally, two hypothetical proteins with CSD-folds and a unique winged helix DNA-binding domain protein were identified in $M$. burtonii, together with a 
«SPAC 11214 layout: Small Condensed v.2.1 file: spac620.tex (ikurtinaitiene) class: spr-small-v1.4 v.2019/10/07 Prn:2019/12/05; 11:32 p. 20/42» doctopic: ReviewPaper numbering style: ContentOnly reference style: aps»

cold shock domain (CSD) protein (homologue of CspA) in M. frigidum (Saunders et al. 2003). In another study, a proteomics approach was taken to analyze the functional characteristics of Methanosarcina barkeri during a low-temperature down shock response (from $37^{\circ} \mathrm{C}$ to $15^{\circ} \mathrm{C}$ ) and for its low-temperature adaptation strategies at $15^{\circ} \mathrm{C}$. In a combined approach using growth studies and proteomics insights into the low-temperature adaptation capacity of M. barkeri could be obtained (Gunnigle et al. 2013). Astrobiologically oriented experiments have been performed to examine the temperature-dependent starvation features of selected Methanosarcina species including M. solegelidi SMA-21, finding that this methanogen tolerated freezing with a survival of $98.5 \%$ in comparison to, e.g., Methanobacterium sp. MC-20, which exhibited only $1 \%$ survival under the same conditions (Morozova and Wagner 2007). M. soligelidi SMA-21 showed a high survival potential at $4{ }^{\circ} \mathrm{C}$ and at $28^{\circ} \mathrm{C}$ compared to other methanogens tested (Morozova and Wagner 2007).

Methanogens possess other physiological adaption mechanisms to changes of growth temperature, for instance the ability to modify cytoplasmic membrane lipids to maintain membrane fluidity. A prerequisite is that the lipid membrane of organisms must be kept in the liquid crystalline phase in order to stay functional, which was found in methanogens over the temperature range between 0 and $100^{\circ} \mathrm{C}$ (Koga 2012).

Membrane fluidity maintenance in psychrophilic methanogens is achieved through growth temperature-mediated lipid saturation instead of the unsaturation mechanisms that occur in bacteria (Nichols et al. 2004). In methanogens, lipid unsaturation is performed by geranylgeranyl reductase. Notwithstanding, the cytoplasmic lipid composition in general, and its unsaturation properties of methanogens in particular, are unclear indicators as to whether a methanogen is adapted to a psychrophilic or a thermophilic lifestyle (Koga 2012).

The core lipids of $M$. thermoautotrophicus growing at its optimal growth temperature of $65^{\circ} \mathrm{C}$ are composed of archaeol and caldarchaeol, whereas the core membrane lipids of M. kandleri, growing at $90^{\circ} \mathrm{C}$, are archaeol (Koga 2012). The core lipids of Methanocaldococcus villosus and Methanothermococcus okinawensis are archaeol and macrocycle (with minute abundances of tetraether lipids) (Baumann et al. 2018) but, upon increasing the growth temperature of Methanocaldococcus jannaschii from $45^{\circ} \mathrm{C}$ to $65^{\circ} \mathrm{C}$, the lipid membrane composition changes from mainly archaeol to macrocycle as well as caldarchaeol (Koga 2012; Sprott et al. 1991). Moreover, the presence of double bonds in isoprenoid chains is not indicative of adaptation to lower growth temperatures (Koga 2012).

The above-mentioned results indicate that mechanisms at the genome level (e.g. the expression of deaD at suboptimal growth temperature), at the proteome level (e.g. activity of EF2), and in the lipid membrane composition distinguishes the adaptations of stenopsychrophilic, eurypsychrophilic and thermophilic methanogens. Other described physiological characteristics of methanogens to cope with adaptations to psychrophilic cultivation conditions include the uptake of compatible solutes (Dong and Chen 2012; Cavicchioli 2006, Grochowski et al. ?gr08). A discussion on the role of compatible solutes as osmoprotective compounds is given below.

\subsection{Adaptions to Pressure}

Methanogens are known to grow under low- and high-pressure conditions. The cultivation of methanogens under high-pressure conditions offers an opportunity for astrobiological studies, for example, the investigation of physiological responses and metabolic adaptations, and for investigating the ecology of hydrothermal vent systems proposed for ocean worlds. Methanogens are known to grow at more than $20 \mathrm{MPa}$ of pressure (Jeanthon et al. 1998, 1999, 2012). The cultivation of methanogens under high-pressure conditions of up to 300 
$\mathrm{kPa}$ can be easily performed in closed batch cultivation in either serum bottles (Taubner et al.?ta16) or in sophisticated cultivation devices such as bioreactors (Nishimura et al. 1992; Seifert et al. 2014). The cultivation of methanogens under low-pressure conditions and at pressures beyond $300 \mathrm{kPa}$ requires special equipment (Kral et al. 2011; Kral and Altheide 2013; Park and Clark 2002; Miller et al. 1988; Boonyaratanakornkit et al. 2006; Taubner et al. 2018). Low-pressure experiments are relevant for astrobiology, to represent the lower above ground pressure present on Mars and other Solar System bodies.

With respect to growth, substrate uptake, and $\mathrm{CH}_{4}$ production kinetics, two methanogens (KN-15 and $M$. marburgensis) examined under moderate high-pressure conditions in fedbatch or continuous culture mode in bioreactors (Nishimura et al. 1992; Seifert et al. 2013; Seifert et al. 2014) have shown that the point at which growth kinetics changed from exponential growth to linear growth (and the specific growth rate $(\mu)$ ) of strain $\mathrm{KN}-15$ increased with increasing pressure (Nishimura et al. 1992). The results obtained for M. marburgensis showed that $\mathrm{CH}_{4}$ production is gas-limited and, although applying high-pressure conditions, the maximum physiological capacity of the organism to produce $\mathrm{CH}_{4}$ was not reached (Seifert et al. 2014).

M. jannaschii was cultivated under gas-limited conditions and it was found that the tested strain exhibited a stress response under both high-pressure and low-pressure cultivation conditions at the transcriptional level (Boonyaratanakornkit et al. 2006). High-pressure and decompression experiments were also performed using $M$. jannaschii, employing a highpressure bioreactor. When rapid decompression from approximately $26 \mathrm{MPa}$ to atmospheric pressure was performed, the cell envelopes of $M$. jannaschii ruptured, however, when the decompression time was increased from $1 \mathrm{~s}$ to $5 \mathrm{~min}$, the rupture of $M$. jannaschii cell envelopes decreased significantly (Park and Clark 2002). In another study, M. jannaschii was used to investigate growth and $\mathrm{CH}_{4}$ production kinetics at high-pressure conditions and at different temperatures, in the presence of $\mathrm{He}$ or $\mathrm{Ar}$ in addition to $\mathrm{H}_{2} / \mathrm{CO}_{2}$. It was found that the high-temperature limit for $\mathrm{CH}_{4}$ production kinetics of $M$. jannaschii increased with increasing pressure (Miller et al. 1988).

Additional high-pressure and high-temperature investigations using Methanococcus thermolithotrophicus were accomplished in $10 \mathrm{~mL}$ nickel tubes in series of connected autoclaves. This experimental setup was used to expose the organism of choice to temperature and high-pressure changes of $400{ }^{\circ} \mathrm{C}$ and $400 \mathrm{MPa}$ over $10 \mathrm{~min}$ to investigate optimum pressure levels (Bernhardt et al. 1987). A pressure of $50 \mathrm{MPa}$ was found to be optimal for the growth of $M$. thermolithotrophicus, whereas applying overpressure of $>75 \mathrm{MPa}$ resulted in increased cell lysis and in changes of morphology and in changes of growth kinetics (Bernhardt et al. 1987).

In a recent study mimicking the concentrations of gaseous and liquid inhibitors as well as high-pressure conditions on Enceladus (Taubner et al. 2018), different pressure conditions with and without gaseous inhibitors were applied to evaluate the viability of methanogens in these environments. It was shown that the methanogenic strain M. okinawensis produced $\mathrm{CH}_{4}$ at pressures up to $9 \mathrm{MPa}$, but only in the presence of molecular nitrogen in the gas phase. Using a $\mathrm{H}_{2} / \mathrm{CO}_{2}$ gas phase at this high pressure results in a high $\mathrm{CO}_{2}$ partial pressure which significantly lowers the $\mathrm{pH}$ of the medium. Under putative Enceladus-like conditions including potential gaseous and liquid inhibitors like crabon monoxide (CO), ethene $\left(\mathrm{C}_{2} \mathrm{H}_{4}\right)$, formaldehyde $\left(\mathrm{CH}_{2} \mathrm{O}\right)$, or methanol $\left(\mathrm{CH}_{3} \mathrm{OH}\right), \mathrm{CH}_{4}$ production was observed up to $5 \mathrm{MPa}$.. The $\mathrm{CH}_{4}$ production kinetics did not change due to the presence of gaseous and liquid inhibitors during experiments between $300 \mathrm{kPa}$ to $5 \mathrm{MPa}$ (Taubner et al. 2018). A simultaneous bioreactor system (SBRS) was developed, consisting of four identical tabletop bioreactors that are suitable for performing gas conversion and gas production kinetics at 
pressures up to 50 bar and temperatures up to $145^{\circ} \mathrm{C}$. M. marburgensis, M. palustre, and $M$. thermaggregans were successfully cultivated at $1 \mathrm{MPa}$ and/or $5 \mathrm{MPa}$ and differences in the $\mathrm{CH}_{4}$ production kinetics of these organisms were detected (Pappenreiter et al. 2019). The SBRS system facilitates throughput high-pressure astrobiological research, which is of timely relevance in assessing the possibility of high-pressure habitats on outer Solar systems bodies.

\subsection{Adapations to $\mathrm{pH}$}

Most of the $>150$ characterized methanogens grow at neutral $\mathrm{pH}$ values (Taubner et al. 2015). Methanogens such as M. okinawensis (Takai et al. 2002; Taubner et al. 2018) and M. marburgensis (Bernacchi et al. 2014) tolerate a broader $\mathrm{pH}$ range down to values of 3.5 and 4.5 , respectively. Furthermore, there are also other methanogens known to be able to grow under acidic pH conditions (Bräuer et al. 2011; Cadillo-Quiroz et al. 2009; Ver Eecke et al. 2013). However, from an astrobiological viewpoint, at least Enceladus' subsurface ocean is rather alkaline (Glein et al. 2015). Currently six alkaliphilic methanogens have been characterized and are available in pure culture (Table 2). The most alkaliphilic methanogens are Methanocalculus natronophilus (Zhilina et al. 2013), Methanocalculus alkaliphilus, and Methanosalsum natronophilum (Sorokin et al. 2015). M. natronophilus was isolated from the sediments of a collector in the vicinity of a soda lake. The strain utilizes $\mathrm{CO}_{2}$ and $\mathrm{H}_{2}$ or formate as an energy source and acetate as a carbon source. M. alkaliphilus and $M$. natronophilum were enriched from hypersaline soda lake sediments at $\mathrm{pH}$ 10. All three alkaliphilic methangogens grow at $\mathrm{pH}$ between 8.2 and 10.0 and optimally around $\mathrm{pH}$ 9.0-9.5. M. alkaliphilus utilizes formate or $\mathrm{H}_{2}$ as an electron donor and acetate as a carbon source, whereas M. natronophilum metabolizes methanol, methylamines, and dimethyl sulfide. Another alkaliphilic and slightly thermophilic methanogen, Methanonatronarchaeum thermophilum was recently characterized. This methanogen comprises a new euryarchaeal class, the Methanonatronarchaea. This organism grows between $\mathrm{pH}$ values of 8.2-10.2 and optimally between $\mathrm{pH}$ 9.5-9.7. M. thermophilum utilizes methanol, methylamines and dimethylsulfide as electron acceptors and formate or $\mathrm{H}_{2}$ as electron donors (Sorokin et al. 2018). A list of methanogens cultivable in either acidic or alkaline conditions is shown in Table 2.

\subsection{Adaption to Osmolarity}

All known methanogens depend on low intracellular salt concentrations to maintain cellular integrity and the functioning of homeostatic processes. For the maintenance of cellular functions at higher extracellular concentrations of salt, some methanogens are known to accumulate compatible solutes to reduce the difference of osmotic potentials between the cytoplasm and the environment. Compatible solutes are osmoprotective molecules (Fig. 1) and do not alter the metabolic and cellular processes, even when accumulated in high concentrations (Jones et al. 1983a, 1983b).

Trimethylglycine (glycine betaine) and $\beta$-glutamate were shown to act as compatible solutes in methanogens, whereby the former can be assimilated by some methanogens from the growth medium (Grochowski et al. ?gr08; Robertson et al. 1990; Lai et al. 1991). Additionally, an adenosine derivate was proposed to act as a compatible solute in Methanolobus psychrophilus R15. Furthermore, it was suggested that some of the compatible solutes described for methanogens could possibly possess cryoprotective functions (Dong and Chen 2012). The main compatible solute utilized by methanogens is trimethylglycine (Robertson 
«SPAC 11214 layout: Small Condensed v.2.1 file: spac620.tex (ikurtinaitiene) class: spr-small-v1.4 v.2019/10/07 Prn:2019/12/05; 11:32 p. 23/42» doctopic: ReviewPaper numbering style: ContentOnly reference style: aps»

Microbial Diversity and Biosignatures: An Icy Moons Perspective

Page 23 of 42

-\#\#\#\#_-

1101

1102

1103

1104

1105

1106

1107

1108

1109

1110

1111

1112

1113

1114

1115

1116

1117

1118

1119

1120

1121

1122

1123

1124

1125

1126

Table 2 Summary of currently known methanogens cultivable in either very acidic or alkaline conditions

\begin{tabular}{|c|c|c|c|c|c|c|c|}
\hline \multirow[t]{2}{*}{ Strain } & \multicolumn{3}{|c|}{$\mathrm{T}\left[{ }^{\circ} \mathrm{C}\right]$} & \multicolumn{3}{|l|}{$\mathrm{pH}$} & \multirow[t]{2}{*}{ Ref. } \\
\hline & $\min$ & opt & $\max$ & $\min$ & opt & $\max$ & \\
\hline Methanospirillum stamsii & 5 & $20-30$ & 37 & 6 & $7-7.5$ & 10 & Parshina et al. (2014) \\
\hline $\begin{array}{l}\text { Methanocalculus } \\
\text { natronophilus }\end{array}$ & 14 & $30-37$ & 45 & 8 & $9-9.5$ & 10.2 & Zhilina et al. (2013) \\
\hline Methanospirillum hungatei & 20 & $37-45$ & 50 & 6.5 & $7-9$ & 10 & Iino et al. (2013) \\
\hline $\begin{array}{l}\text { Methanobrevibacter } \\
\text { millerae }\end{array}$ & 33 & $36-42$ & 43 & 5.5 & $7-8$ & 10 & Rea et al. (2007) \\
\hline $\begin{array}{l}\text { Methanobrevibacter } \\
\text { olleyae }\end{array}$ & 28 & $28-42$ & 42 & 6 & 7.5 & 10 & Rea et al. (2007) \\
\hline Methanotorris igneus & 45 & 88 & 91 & 5 & 5.7 & 7.5 & Burggraf et al. (1990) \\
\hline $\begin{array}{l}\text { Methanosphaerula } \\
\text { palustris }\end{array}$ & 14 & 30 & 35 & 4.8 & 5.5 & 6.4 & $\begin{array}{l}\text { Cadillo-Quiroz et al. } \\
\text { (2009) }\end{array}$ \\
\hline Methanoregula boonei & 10 & $35-37$ & 40 & 4.5 & 5.1 & 5.5 & Bräuer et al. (2011) \\
\hline $\begin{array}{l}\text { Methanothermococcus } \\
\text { okinawensis }\end{array}$ & 40 & $60-65$ & 75 & 3.5 & $6-7$ & 8.5 & $\begin{array}{l}\text { Takai et al. (2002), } \\
\text { Taubner et al. (2018) }\end{array}$ \\
\hline $\begin{array}{l}\text { Methanonatronarchaeum } \\
\text { thermophilum }\end{array}$ & 30 & 50 & 60 & 8.2 & $9.5-9.7$ & 10.2 & Sorokin et al. (2018) \\
\hline
\end{tabular}

et al. 1990), which is used by e.g. Methanosarcina thermophila TM-1 (Proctor et al. 1997) and can be accumulated through an uptake system composed of a single, high-affinity $\mathrm{H}^{+}$and/or $\mathrm{Na}^{+}$-driven transporters (Proctor et al. 1997). M. thermophila TM-1 can adapt to different osmolarities by synthesizing $\alpha$-glutamate and $\mathrm{N}$ - $\varepsilon$-acetyl- $\beta$-lysine, or by accumulating trimethylglycine or $\mathrm{K}^{+}$. In Methanohalophilus portucalensis FDF1, the compatible solutes $\alpha$-glutamate, $\beta$-glutamine, and $\mathrm{N}$ - $\varepsilon$-acetyl- $\beta$-lysine were described as osmoprotectives (Lai et al. 1991, 2000), whereas trimethylglycine was preferentially taken up from the medium as an osmoprotective compound instead of being produced de novo (Lai et al. 2000).

Many experiments examining the effect of osmolarity have used Methanosarcinales. $\mathrm{NaCl}$ concentrations from 0.05 to $1.0 \mathrm{~mol} \mathrm{~L}^{-1}$ were used to examine the effect of osmolarity on growth kinetics and changes of morphology in Methanosarcina spp. (Sowers et al. 1993) and $\mathrm{NaCl}$ concentrations between 0.4 to $1.0 \mathrm{~mol} \mathrm{~L}^{-1}$ disintegrated the methanochondroitin and sheath, which resulted in growth of Methanosarcina spp. as single cells. Furthermore, all tested Methanosarcina spp., which were encapsulated by a methanochondroitin layer, exhibited enhanced stability to $<0.2 \mathrm{~mol} \mathrm{~L}^{-1} \mathrm{NaCl}$ osmolarity and grew at higher temperatures compared to the control group (Sowers et al. 1993).

An adaptation to high salt concentrations was shown with Methanosarcina mazei Gö1. The strain was able to tolerate up to $1 \mathrm{~mol} \mathrm{~L}^{-1}$ salt through the uptake and accumulation of trimethylglycine from the growth medium. The osmoprotectant transporter A (OpuA) was involved in trimethylglycine uptake from the medium and its expression was demonstrated to be salt-induced (Roeßler et al. 2002).

Methanohalophilus spp. strains grown at different $\mathrm{NaCl}$ concentrations between 0.7 to $3.4 \mathrm{~mol} \mathrm{~L}^{-1}$ demonstrated that the strains accumulated $\mathrm{K}^{+}$, however, the osmoprotective $\beta$-glutamate was detected when the strains were grown at $\mathrm{NaCl}$ concentrations of $<1.5 \mathrm{~mol} \mathrm{~L}^{-1}$ (Lai et al. 1991).

The alkaliphilic methanogens M. natronophilus (Zhilina et al. 2013), M. alkaliphilus and M. natronophilum (Sorokin et al. 2015), and M. thermophilum (Sorokin et al. 2018) 
«SPAC 11214 layout: Small Condensed v.2.1 file: spac620.tex (ikurtinaitiene) class: spr-small-v1.4 v.2019/10/07 Prn:2019/12/05; $11: 32$ p. 24/42» doctopic: ReviewPaper numbering style: ContentOnly reference style: aps»

are slightly halophilic, extreme halotolerant, and extreme halophilic, respectively, i.e., they exhibit polyextremophily. Optimal growth of M. natronophilus requires carbonate concentrations of $0.7-0.9 \mathrm{~mol} \mathrm{~L}^{-1}$ and $\mathrm{Na}^{+}$at concentrations of $1.4-1.9 \mathrm{~mol} \mathrm{~L}^{-1}$. M. alkaliphilus is characterized as a moderately salt-tolerant strain within the range from 0.2 to $1.5 \mathrm{~mol} \mathrm{~L}^{-1}$ total $\mathrm{Na}^{+}$in carbonate buffer at a $\mathrm{pH}$ of 9.5. M. natronophilum is highly salt-tolerant in a range from 0.5 to $3.5 \mathrm{~mol} \mathrm{~L}^{-1}$ total $\mathrm{Na}^{+}$growing also in carbonate buffer at a $\mathrm{pH}$ of 9.5 . The recently described $M$. thermophilum is an extremely halophilic organism growing at total $\mathrm{Na}^{+}$concentrations between 3 and $4.8 \mathrm{~mol} \mathrm{~L}^{-1}$ with an optimum at $4 \mathrm{~mol} \mathrm{~L}^{-1}$, and its cells lyse at a $\mathrm{Na}^{+}$concentration below $2 \mathrm{~mol} \mathrm{~L}^{-1}$. M. thermophilum accumulates $\mathrm{K}^{+}$as its main compatible solute.

The above described characteristics and adaptations towards low- and high-pressure conditions, psychrophily and (hyper)thermophily, acidiphily and alkaliphily and osmolarity reveal that methanogens thrive under a variety of extreme growth conditions, but also during multi-factorial stress conditions (e.g. simulataneous multivariate concentrations of gaseous and liquid inhibitors, low $\mathrm{pH}$, and pressure influences) and they respond to environmental disturbances in numerous ways (Kral et al. 2011; Taubner et al. 2015, 2018). Further, as already mentioned in Sect. 2.1.1 of this review, no other archaeal halophiles than methanogens have been identified outside the Euryarchaea. Only one recently characterized halophilic methanogen, $M$. thermophilum, is uses the salt-in-cytoplasm strategy for osmoprotection and other methanogens employ the organic-osmolyte strategy to deal with osmotic stress. Hence, with respect to their potential to adapt to changing and extreme environmental conditions, methanogens are considered to be among the ideal candidates for further astrobiological studies.

\section{Origins of Life and Biosignatures on Icy Worlds}

\subsection{Ocean World Settings for the Origins of Life}

In any origins of life scenario, prebiological chemical complexification would have necessitated the confined or compartmentalized reaction of ions and molecules within an aqueous geological setting characterized by gradients and disequilibria (Russell et al. 2010). Over time, prebiotic complexification would have driven the system closer to obtaining life-like characteristics (e.g., metabolism, replication). The step(s) linking the immediate life-like precursor to the first living entity (i.e., a pioneer organism) are the most contentious (e.g. Wächtershäuser ?wa88; Martin and Russell 2003; Russell et al. 2010), and will not be covered in this review. A number of geological settings for the origins of life have been proposed. These settings are generally hydrothermal (submarine or subaerial hot springs) or hydrothermally influenced (the hydrothermal-sedimentary reactor hypothesis), though others are passive and rely on providing naturally reactive mineral-rich environments as "reactor flasks" for organic molecules sourced from elsewhere, for example, the pumice raft hypothesis (Brasier et al. ?br11). Further possibilities, as yet incompletely explored, are the geodynamic nuclear reactor hypothesis (Ebisuzaki and Maruyama ?em17) or the hydrodynamically driven volcanic-hosted splash pool hypothesis (Fox and Strasdeit ?fs13). A review of all of these hypotheses, culminating in a suggestion that the cycling of organicrich fluids through the volcanogenic sediments in the vicinity of hydrothermal fields (the hydrothermal-sedimentary scenario for the origin of life), is given in Westall et al. (2018).

Despite the wide range of propositions behind the mechanics of the origins of life, most hypotheses for the geological setting of this process focus on either submarine or subaerial 
hydrothermal environments. Such settings are supported by both the top-down and bottomup approaches to the origins of life. From the viewpoints of organic chemistry and geochemistry, hydrothermal settings produce, and have the potential to concentrate within geological (mineral) edifices, the range of simple organic monomers and polymers whose gradual complexification theoretically leads to 'protocells' and cellular life (Russell et al. 2010; Lane and Martin 2012; Westall et al. 2018). From the biological viewpoint, estimations of the nature and metabolism of the earliest life invariably find a root in thermophilic, metalrich settings (Nisbet and Fowler ?nf96; Williams and Fraústo Da Silva 2003; Gaucher et al. ?ga10; Lane and Martin 2012). Whether life originated in the submarine or subaerial arena is a topic of contention, focused on the specific characteristics and parameters of the organic chemistry and geochemistry possible in these settings that may lead to prebiotic chemical complexification.

Certainly, it is necessary that the geological environment of the origin of life was able to naturally produce or directly receive a wide range of organic molecules. Chemical complexification requires that this production is harnessed by a combination of gradient-driven compartmentalized or confined milieu composed of mineral surfaces, preferably chiral (Martin and Russell 2003; Hazen and Sverjensky 2010; Dass et al. 2018). Gradients in temperature, salinity, redox state, and $\mathrm{pH}$ are natural disequilibrium drivers that are implicated in chemical evolution, and mineral surfaces are considered equally necessary for abiogenesis, given their ability to chelate and determine the conformation of molecules concentrated at their surfaces (Hazen and Sverjensky 2010). Whether mineral phases act purely as the catalytic forces of conformation, or have morphologies at the microscale that drive the concentration of organic molecules and favor forward reaction dynamics (e.g. Parsons et al. ?pa98), the role of minerals in systems chemistry models for the origins of life is irrefutable. These three factors-organic molecule production, reaction concentration and substrate availabilityare necessary prerequisites for an environment to be considered as a potential theatre for the origins of life (Westall et al. 2018).

Further constraints, such as whether the fluid dynamics of the environment are appropriate for long-term turbid mixing of molecule-mineral mixtures, and whether temperatures favor forward complexification or backward molecular simplification reactions are yet to be fully assessed (Westall et al. 2018). The timescales involved in the environmental and organic chemistry processes and the lifetime of the environment itself are further parameters to be considered. In this regard, subaerial hot spring systems are less compelling than their submarine equivalents; however, hydrothermal fields of all types may endure for over several million years (Martin and Russell 2007; Westall et al. 2018; Cavalazzi et al. 2019). On the early Earth, geological longevity of subaerial environments would have been limited by periodic destruction by impactors, which were incident upon the Earth at a frequency up to hundreds or thousands of times higher than at present (Koeberl 2006; Sleep 2018; Pearce et al. 2018). Notwithstanding, the recent re-evaluation of the severity of the Late Heavy Bombardment means that planet-sterilizing impact events may have been very uncommon (Zellner ?za17). Recent schemes for long-term chemical evolution in subaerial hot springs (Van Kranendonk et al. 2017) would, however, be significantly limited by such temporal constraints, since environments that were not protected by an oceanic covering would have been susceptible to irrevocable alteration and destruction on potentially shortterm periodic cycles. For this reason, ocean worlds deserve recognition as hosting habitable environments that may have allowed the origin and proliferation of life (Lammer et al. ?la09; Barge and White ?bw17). Enceladus is the ideal test case, given that the proposed conditions at its ocean floor or in its plumes may be simulated in the laboratory as part of experiments with astrobiological application (Barge and White ?bw17; Taubner et al. 2018). 
Both Enceladus and Europa are thought to have an internal structure that includes a contact zone between the ocean layer and the underlying silicate crust (Kargel et al. ?ka00; Chyba and Phillips ?cp01; McKay et al. ?mc18). Devolatilization of the rocky crust or mantle of these moons would conceivably lead to hydrothermal effluent generation, which could have produced local oceanic conditions conducive to habitability and prebiotic chemistry through providing an aqueous environment with an adequate energy source, the production of bio-essential elements and organic monomers and oligomers, and disequilibrium conditions in the form of temperature and pressure gradients (Kargel et al. ?ka00; Lammer et al. ?la09). Ocean worlds are therefore potential localities for a second, possibly independent, origin of life in the Solar System. Assuming that life could have arisen on the icy moons of the outer Solar System, the question for palaeobiologists becomes one of the nature of traces of life that might be preserved and detectable. This poses a range of challenges very different to the extant life discussed thus far.

\subsection{Ancient Traces of Life and Their Lessons for Biosignature Detection on Ocean Worlds}

Robust evidence for life on Earth dates back to at least $3.481 \mathrm{Ga}$, based on critical studies of the stromatolites of the Dresser Formation (Walter et al. 1980; Van Kranendonk et al. 2006; Hickman-Lewis et al. ?h119). The Dresser Formation stromatolites do not preserve unambiguous evidence of the microfossil architects themselves, for which further detailed studies beyond current carbon isotope work (Ueno et al. ?ue01, 2006) are required, but rather lamination characteristics in the organo-sedimentary structure that are demonstrated to have biological morphogenesis (Hickman-Lewis et al. ?hl19). Nonetheless, it is highly probable that these stromatolites are photosynthetic in origin, and are thus not of direct relevance to the habitable realms of ocean worlds, which demand chemosynthetic metabolic networks. Aside from the Dresser Formation, the oldest generally accepted fossiliferous horizons - those that have undergone and resisted some level of scientific criticism-are the 3.44 Ga Kitty's Gap Chert (Westall et al. 2006, 2011), the 3.43 Ga Strelley Pool Formation (Hofmann et al. 1999; Allwood et al. 2007) and the 3.42 Ga Buck Reef Chert (Tice and Lowe 2004; Tice 2009; Greco et al. 2018), although the first two examples are not without their critics (Lowe 1994; Lindsay et al. 2005; Wacey 2009). Comparably ancient Palaeoarchaean fossiliferous material has more recently been described from the 3.47 Ga Middle Marker horizon (Hickman-Lewis et al. 2018), the 3.46 Ga stratiform Apex chert (Hickman-Lewis et al. 2016) and the 3.27 Ga Mendon Formation (Trower and Lowe 2016). With continued study at ever higher resolutions and ever more careful scrutiny, these and other examples may or may not emerge as widely accepted biosignatures. At the limit of the geological record, proposed Eoarchaean biosignatures have been described from the $>3.7$ Ga Isua supracrustal belt of Greenland (Rosing 1999; Nutman et al. 2016; Hassenkam et al. 2017), and the $>3.7$ Ga Nuvuagittuq greenstone belt (Dodd et al. 2017) and $>3.8$ Ga Saglek Block (Tashiro et al. 2017) of Canada, but these are considerably more controversial. The iron-rich filament-like structures in hydrothermal deposits described by Dodd et al. (2017) have been reconsidered as volcanic glass (Wacey et al. ?wa18), whereas the putative stromatolites described by Nutman et al. (2016) have been found to more closely resemble metamorphosed carbonate sedimentary textures resulting from compression (van Zuilen ?zu18; Allwood et al. ?al18). The carbon isotopes described by Rosing (1999) in Greenlandic sediments are, however, distinctly more robust, since the average value, $\delta 13 \mathrm{C}=-19 \%$, is consistent with the simple Chloroflexus-like microbial consortia coupled with archaeal methanogens, i.e., an ecosystem dominated by the 
«SPAC 11214 layout: Small Condensed v.2.1 file: spac620.tex (ikurtinaitiene) class: spr-small-v1.4 v.2019/10/07 Prn:2019/12/05; $11: 32$ p. 27/42» doctopic: ReviewPaper numbering style: ContentOnly reference style: aps»

Microbial Diversity and Biosignatures: An Icy Moons Perspective

Page 27 of 42

-\#\#\#\#-

acetyl-CoA or propionyl-CoA pathway, that is suspected to dominated the primary productivity on Earth prior to the advent of oxygenic photosynthesis (Nisbet and Fowler 1999).

In all cases, putative fossil biosignatures must meet three benchmark criteria: (i) they should possess features or signatures (morphological, structural and geochemical) consistent with biology; (ii) they should be syngenetic with their host rock; and (iii) the host rock should evidence a geological setting consistent with habitability. The order in which this assessment is made is of little consequence to proposing a biosignature, since failure to meet even one of the three criteria is sufficient to preclude a feature being adjudged of palaeobiological significance. Having been submitted to several billion years of processes capable of changing them beyond recognition, the identification and analysis of the most ancient biosignatures can be fraught with difficulties. On Earth, the fundamental dichotomy between Eoarchaean and Palaeoarchaean-Mesoarchaean fossil-like remains is the difference in metamorphic grade between the host rocks, which can be approximately summarized as "up to amphibolite facies" and "up to greenschist facies", respectively. Consequently, the stratigraphic, geochronological and eventual biogeochemical constraints able to be placed upon Eoarchaean traces of life are far less robust than those for the Palaeoarchaean (Whitehouse et al. 2019). This has resulted in a range of putative Eoarchaean biosignatures postulated based on geochemistry and geochronology, and for which biogeochemistry is criticized subjectively, contrasted with a range of Palaeoarchaean biosignatures evaluated by microbial palaeontology and biogeochemistry, and whose fossiliferous nature can be assessed objectively. In all biosignatures assessment, the first task is to determine whether the purported signature is truly of biogenic origin and not an abiotic look-alike (biomorph) or artefact. Microbial structures and constructs, both macroscopic and microscopic, often have very simple shapes that can be imitated by abiotic processes (Garcia-Ruiz et al. ?gr03; Westall et al. 2006; Rouillard et al. ?ro18): spheroidal microfossils may be easily confused with spheroidal mineral precipitates, such as silica, while a sheet-like concentration of abiotic organic material could, without microscopic assessment, superficially resemble a biofilm. Disseminated organic matter in ancient sediments, especially when significantly degraded, needs to be distinguished from abiotic organic matter of hydrothermal or other origin. A noteworthy case study of controversial biogenicity is presented by the microfossil-like objects of the $3.46 \mathrm{Ga}$ "Apex Chert," Western Australia. Although initially interpreted as organisms with a cyanobacterial affinity (Schopf and Packer ?sp87; Schopf ?sc92), later studies of the same material gradually unravelled the case for their biogenicity (Brasier et al. ?br02, ?br05, ?br06; Wacey et al. ?wa16). Although of superficially microfossil-like morphology (filamentous, apparently septate), high-resolution FIB-SEM work demonstrated that this morphology results from aluminous clay minerals onto which carbon had become fortuitously adhered (Brasier et al. ?br15; Wacey et al. ?wa16). Recent isotopic studies suggesting morphotype-specific carbon isotope fractionation indicative of a mixed methanogen-methanotroph community (Schopf et al. ?sh17) mean that this particular controversy is ongoing. Such cases of controversial or mistaken biogenicity plague biosignatures of all sizes, up to and including stromatolites. A famous (albeit extreme) example thereof is the "Taylor stromatolite," a complex laminar-domical structure closely resembling modern stromatolites but having been created by coincidence during paint spraying in the mid-Twentieth Century. Similar supposed abiological examples are known from the geological record, and especially ancient stromatolitic occurrences, such as the 3.481 Ga Dresser Formation and 3.43 Ga Strelley Pool Formation stromatolites, have been routinely subject to strong criticism (Lowe 1994; Lindsay et al. 2005) in spite of bearing many biological characteristics (Walter et al. 1980; Van Kranendonk ?kr07; Hickman-Lewis et al. 2016, ?hl19). At the time of writing, scientific consensus on these stromatolites suggests that their origin is biological. 
Having established the biogenicity of the feature, the second task is to establish its syngenicity with the host rock. Microbes may infiltrate cracks and fissures in rocks of various ages (as chasmoliths or endoliths) and can become fossilised in their endo-/chasmolithic habitats. Westall and Folk (?wf03), for example, demonstrated that organisms previously considered syngenetic within $\sim 3.8 \mathrm{Ga}$ rocks from the Isua supracrustal belt are in fact Holocene endolithic cyanobacteria. The case for syngenicity in carbonaceous microfossils on Earth is often strengthened by Raman spectroscopy demonstrating that the carbonaceous material and its host rock have equivalent thermal histories (e.g. van Zuilen et al. ?zu07; Marshall et al. ?ma07)

The third, governing consideration in biogenicity is the environment of formation, i.e., does the purported biosignature occur in a geological context consistent microbial habitability? Most such proof in ancient successions relies on a combination of sedimentology and trace and rare earth element geochemistry (e.g., Lowe and Byerly ?1b99; Hofmann and Bolhar ?hb07) and shows that early Earth environments were strongly influenced by volcanogenic inputs and hydrothermal fluids that are manifested as silicification zones in basalts beneath chert horizons.

\subsection{Fossil Microbial Biosignatures Relevant to Ocean Worlds}

As highlighted in the earlier sections of this review, the diversity of microbial biosignatures of relevance to ocean worlds is vastly reduced when compared to that of Earth due to the fact that all habitable environments on ocean worlds, particularly those at the seafloor, many tens of kilometres beneath the outer icy covering, would have been polyextremophilic. Accordingly, 'highly evolved' Palaeoarchaean microbial mat communities may reflect a degree of biological complexity beyond that possible on Enceladus or Europa. Proposed primitive, uncomplicated biofilm communities that may be evidenced in the Eoarchaean fossil record may be of more relevance, reflecting hyperthermophile, non-photosynthetic autotrophic communities (Nisbet and Fowler ?nf96, 1999; Rosing 1999). Methanogens are among the proposed earliest independent lineages in the tree of life, diverging from Euryarchaeota before $3.51 \mathrm{Ga}$ and perhaps as early as 3.8-4.1 Ga (Battistuzzi et al. ?ba04; Wolfe and Fournier ?wf18). Having numerous extremotolerances that make them suitable candidate organisms for ocean world biomes (Taubner et al. 2015, 2018), understanding biosignatures of methanogenic life in the fossil record may be informative for their detection on ocean worlds. The obvious caveat to this section of the review is that it would be extremely challenging to access and analyse an extinct biosphere within the crust of either Europa or Enceladus.

Most evidence for methanogenesis in the fossil record relies upon carbon isotope ratios measured by in situ secondary ion mass spectrometry, since methanogenesis is characterized by a range of $\delta 13 \mathrm{C}$ values mostly falling between -5 and $-41 \%$, i.e., with values slightly to significantly more negative than other major metabolic pathways-rubisco-mediated photosynthesis, sulphate reduction, photoferrotrophy-evidenced in the fossil record at the same time (Schidlowski ?sc88; Vieth and Wilkes ?vw09). Their more negative carbon isotope fractionations can thus be used to indicate the presence of both Bacteria and Archaea in fossilized biomass (Hayes ?ha94; Nisbet and Fowler 1999). The carbon isotope record therefore provides independent support for the molecular clock estimations of methanogenesis as early as $3.8 \mathrm{Ga}$ by virtue of highly $13 \mathrm{C}$ depleted carbonaceous material in Greenlandic rocks (Grassineau et al. ?gr05). Extreme depletions of up to $-60 \%$ in carbonaceous material from Palaeoarchaean horizons have been used as implicit evidence for coupled methanogenesis and methanotrophy in widespread microbial ecosystems (Hayes ?ha94; Schopf et al. ?sc17; Lepot et al. ?1e19). 
For ocean worlds, traces of planktonic life might also be among the key biosignatures for a fossil biosphere. Prior to the advent of oxygenic photosynthesis, planktonic life seems essentially limited to the hypothesised modes of life of large spheroidal and lenticular microfossils described from numerous horizons in the East Pilbara terrane and the Barberton greenstone belt, although this is likely a function of preservational potential. Indeed, planktonic life away from hydrothermal vents is considered to have had the opportunity to proliferate once organisms had adapted to oligotrophy (e.g., Nisbet and Fowler 1999; Brasier et al. ?br06). In Archaean metasediments, spheroidal and lenticular microfossils up to several hundred microns in size and with interpreted robust cellular morphologies (thickened, spore-like cell walls) span more than $400 \mathrm{Ma}$ of geological history, from the 3.4 Ga Strelley Pool Formation (Sugitani et al. 2015) and Kromberg Formation (Walsh 1992; Oehler et al. 2017) to the 3.0 Ga Farrell Quartzite (Sugitani et al. 2007). These microfossils are characterised by strongly negative carbon isotope fractionation $(\delta 13 \mathrm{C}=-30$ to $-45 \%$ o), consistent with biological origin and sufficiently restricted in range as to preclude origin in abiogenic chemical reactions such as the Fischer-Tropsch type processes (House et al. 2013; Oehler et al. 2017). The highly negative depletions may also be consistent with methane cycling, but this has yet to be unambiguously demonstrated (Oehler et al. 2017). Particularly enigmatic amongst these microfossil-like objects are the lenticular microfossils. The nearequant morphologies of lenticular microfossils, together with the flange-like appendages that characterise their equatorial regions, have been used as specific evidence for their having a planktonic stage in their life cycle (Sugitani et al. 2007, 2015; Oehler et al. 2017). Fluid dynamic modelling of virtual flanged cells has demonstrated both that the presence of the flange reduces sedimentation velocity and enlarges cell volume, two factors increasing their propensity for suspension and dispersion as part of a planktonic lifestyle (Kozawa et al. 2018). Dispersion may further be inferred from the widespread distribution of these fossils in space, i.e. across two Archaean landmasses (the Pilbara and Kaapvaal regions). Although many of these microfossils are solitary occurrences, some pairs, clusters and chains of lenticular objects have been described, particularly in the examples from Western Australia, strongly increasing the case for their biogenicity (see Sugitani 2018).

In contrast to coccoidal and filamentous microfossils from the same formations (Walsh 1992; Walsh and Lowe 1999; Westall et al. 2001), lenticular and large spheroidal microfossils typically show no strict association with stromatolitic or mat-like laminations, which imply that they are not involved in the mat-building process. Although this can be seen as implicit support for a planktonic lifestyle, instances of lenticular carbonaceous objects from the Middle Marker horizon do indeed occur within microbial mats (Hickman-Lewis et al. 2018). While this does not argue against their biogenic origin, their evident simultaneous formation with microbial mats in this unique case warrants further investigation.

The thick cell walls that characterize these organisms have been argued to be beneficial to open ocean modes of life. Oehler et al. (2017) interpreted that such thick walls may have enabled the cells to withstand high levels of UV radiation, metal toxicity, or sudden evapotranspiration events and associated salt stress that may have characterised early Earth habitats (see Lowe et al. 2014; Lowe and Byerly 2015). The potential for dispersion and longevity may also have permitted robust, lenticular cell-like objects to withstand localscale environmental stresses inherent to ocean worlds in ways that more fragile organisms with thinner cell walls could not. The application of the microfossil record to ocean worlds remains very much an open topic; indeed, limited, if any, discourse on the subject had been attempted before this review.

The true challenge of a correlative microscopy approach in palaeobiology applied to the putative biomes of an oceanic celestial body such as Europa and Enceladus lies in the dif- 
«SPAC 11214 layout: Small Condensed v.2.1 file: spac620.tex (ikurtinaitiene) class: spr-small-v1.4 v.2019/10/07 Prn:2019/12/05; 11:32 p. 30/42» doctopic: ReviewPaper numbering style: ContentOnly reference style: aps»

ficulty inherent in accessing samples. At present, no mission objectives involve the assessment of the crust of an ocean world due to the near-insurmountable challenge of reaching the required localities. This section of the review may therefore be little more than intellectual discourse. Nonetheless, one can state that deducing the geology and geochemistry of putative hydrothermal vent deposits on Europa or Enceladus would open up the possibility to appraise the habitable niches of ocean worlds and consider the likelihood of a fossilised biosphere of purely chemotrophic life. Such a biosphere may be an excellentand indeed a truly pristine-analogue for the most primitive (hyper)thermophile biospheres on the Hadean-Eoarchaean Earth.

\section{Conclusions}

Life, especially in the form of microorganisms, has achieved colonization of almost all areas on Earth, even the most hostile and extreme parts of the planet. Organisms have adapted by tailoring their cellular constituents to operate also at the boundaries and limits of life. Microorganisms have been successful in diversifying their metabolisms and taking benefit of the resources available in environments which might be low in the levels of nutrients or extreme in its physical conditions. In these harsh environments they manage to generate enough energy to ensure a minimum of maintenance of cellular constituents and even to proceed reproduction. This metabolic adaptation and diversity of microorganisms has been illustrated by the ability of microorganisms to produce energy from different types of substrates, to produce different types of molecules, such as those that make membranes more robust or those that are characteristic in the response to different stresses whose harmful effects normally cause the denaturation of most cellular components and finally leads to cellular death.

The extent of microbial diversity on Earth is far from being fully elucidated, particularly in remote and extreme environments such as deep sea and subsurface sediments. Organisms living in extreme environments and in particular microorganisms have, over the evolutionary process, developed a large variety of adaptive strategies. As a result, they present a repertoire of original metabolic pathways and biomolecules that allow them not only to survive in extreme conditions, but often to grow in an optimal way in extreme ecological niches. Metabolic markers such as membrane lipids (saturated and polyunsaturated fatty acids, archeaol and caldarcheaol, etc.), compatible solutes (amino acids and derivatives, sugars and derivatives, polyols) or gas production (e. g. methane), witnesses of biological activity, have been detected in increasingly improbable environments previously considered sterile: thermal springs, hydrothermal vents, acidic lakes, alkaline lakes, hypersalines, deep marine sediments, oil reservoirs, glaciers, etc. The physico-chemical and energetic characteristics of some extreme terrestrial environments are analogous to those of other planets and icy moons in the Solar System, which raises the question of the past or present existence of life on these planets and icy moons, or the fulfilment of all the conditions for another origin of life. Biomolecules or biosignatures such as those listed in this chapter can be traced to detect early clues to potential extraterrestrial biological activity.

Publisher's Note Springer Nature remains neutral with regard to jurisdictional claims in published maps and institutional affiliations.

\section{References}

F. Abe, Effects of high hydrostatic pressure on microbial cell membranes: structural and functional perspectives. Sub-Cell. Biochem. 72, 371-381 (2015) 
"SPAC 11214 layout: Small Condensed v.2.1 file: spac620.tex (ikurtinaitiene) class: spr-small-v1.4 v.2019/10/07 Prn:2019/12/05; $11: 32$ p. 31/42» doctopic: ReviewPaper numbering style: ContentOnly reference style: aps»

Microbial Diversity and Biosignatures: An Icy Moons Perspective

Page 31 of 42

-\#\#\#_-

1501

A. Aertsen, F. Meersman, M.E. Hendrickx, R.F. Vogel, C.W. Michiels, Biotechnology under high pressure: applications and implications. Trends Biotechnol. 27(7), 434-441 (2009)

P.S. Aguilar, D. de Mendoza, Control of fatty acid desaturation: a mechanism conserved from bacteria to humans. Mol. Microbiol. 62, 1507-1514 (2006)

E.E. Allen, D. Facciotti, D.H. Bartlett, Monounsaturated but not polyunsaturated fatty acids are required for growth of the deep-sea bacterium photobacterium profundum SS9 at high pressure and low temperature. Appl. Environ. Microbiol. 65, 1710-1720 (1999)

A.C. Allwood, M.R. Walter, I.W. Burch, B.S. Kamber, 3.42 billion-year-old stromatolite reef from the Pilbara Craton of Western Australia: ecosystem-scale in- sights to early life on Earth. Precambrian Res. 158, 198-227 (2007)

J. Antón, R. Rossello-Mora, F. Rodríguez-Valera, R. Amann, Extremely halophilic bacteria in crystallizer ponds from solarsalterns. Appl. Environ. Microbiol. 66, 3052-3057 (2000)

J. Antón, A. Oren, S. Benlloch, F. Rodríguez-Valera, R. Amann, R. Rosselló-Mora, Salinibacter ruber gen. nov., sp. nov., a novel extreme halophilic member of the bacteria from saltern crystallizer ponds. Int. J. Syst. Evol. Microbiol. 52, 485-491 (2002)

A. Antunes, Extreme Red Sea: life in the deep-sea anoxic brine lakes, in Red Sea VI Proceedings, ed. by A. Agius, E. Khalil, E. Scerri (E.J. Brill, Leiden, 2017)

A. Antunes, D.K. Ngugi, U. Stingl, Microbiology of the Red Sea (and other) deep-sea anoxic brine lakes. Environ. Microbiol. Rep. 3, 416-433 (2011)

A. Antunes, S. Kaartvedt, M. Schmidt, Geochemistry and life at the interfaces of brine-filled deeps in the Red Sea, in Oceanography and Environment of the Red Sea II. Springer Earth System Sciences 2018 (Springer, Berlin, 2018)

A. Antunes, K. Olsson-Francis, T. McGenity, Exploring deep-sea brines as potential terrestrial analogues of oceans in the icy moons of the outer solar system. Curr. Issues Mol. Biol. (2020, accepted)

D.H. Bartlett, Pressure effects on in vivo microbial processes. Biochim. Biophys. Acta 1595, 367-381 (2002)

L.M.F. Baumann, R.-S. Taubner, T. Bauersachs, M. Steiner, C. Schleper, J. Peckmann, S.K.-M.R. Rittmann, D. Birgel, Intact polar lipid and core lipid inventory of the hydrothermal vent methanogens Methanocaldococcus villosus and Methanothermococcus okinawensis. Org. Geochem. 126, 33-42 (2018)

J. Beranova, M. Jemiola-Rzeminska, D. Elhottova et al., Metabolic control of the membrane fluidity in Bacillus subtilis during cold adaptation. Biochim. Biophys. Acta, Biomembr. 1778, 445-453 (2008)

S. Bernacchi, S. Rittmann, A.H. Seifert, A. Krajete, C. Herwig, Experimental methods for screening parameters influencing the growth to product yield $(\mathrm{Y}(\mathrm{x} / \mathrm{CH} 4))$ of a biological methane production (BMP) process performed with Methanothermobacter marburgensis. AIMS Bioeng. 1, 72-86 (2014)

G. Bernhardt, R. Jaenicke, H.D. Ludemann, High-pressure equipment for growing methanogenic microorganisms on gaseous substrates at high temperature. Appl. Environ. Microbiol. 53, 1876-1879 (1987)

J.L. Birrien, X. Zeng, M. Jebbar, J. Querellou, P. Oger, M.A. Cambon-Bonavita, X. Xiao, D. Prieur, Pyrococcus yayanosii sp. nov., the first obligate piezophilic hyperthermophilic achaeon isolated from a deep-sea hydrothermal vent. Int. J. Syst. Evol. Microbiol. 61, 2827-2831 (2011)

C.E. Blank, Phylogenomic dating - the relative antiquity of archaeal metabolic and physiological traits. Astrobiology 9, 193-219 (2009)

E. Blöchl, R. Rachel, S. Burggraf, D. Hafenbradl, H.W. Jannasch, K.O. Stetter, Pyrolobus fumarii, gen. and sp. nov., represents a novel group of archaea, extending the upper temperature limit for life to 113 degrees C. Extremophiles 1(1), 14-21 (1997)

H. Bolhuis, E.M. Poele, F. Rodriguez-Valera, Isolation and cultivation of Walsby's square archaeon. Environ. Microbiol. 6, 1287-1291 (2004)

B. Boonyaratanakornkit, J. Córdova, C.B. Park, D.S. Clark, Pressure affects transcription profiles of Methanocaldococcus jannaschii despite the absence of barophilic growth under gas-transfer limitation. Environ. Microbiol. 8, 2031-2035 (2006)

T. Bosak, S. Greene, D.K. Newman, A likely role for anoxygenic photosynthetic microbes in the formation of ancient stromatolites. Geobiology 5, 119-126 (2007)

T. Bosak, A.H. Knoll, A.P. Petroff, The meaning of stromatolites. Annu. Rev. Earth Planet. Sci. 41, 21-44 (2013)

S.L. Bräuer, H. Cadillo-Quiroz, R.J. Ward, J.B. Yavitt, S.H. Zinder, Methanoregula boonei gen. nov., sp. nov., an acidiphilic methanogen isolated from an acidic peat bog. Int. J. Syst. Evol. Microbiol. 61, 45$52(2011)$

C. Brochier-Armanet, P. Forterre, S. Gribaldo, Phylogeny and evolution of the Archaea: one hundred genomes later. Curr. Opin. Microbiol. 14, 274-281 (2011)

J.J. Brocks, G.A. Logan, R. Buick, R.E. Summons, Archean molecular fossils and the early rise of eukaryotes. Science 285, 1033-1036 (1999)

A.D. Brown, Microbial water stress. Bacteriol. Rev. 40, 803-846 (1976) 
«SPAC 11214 layout: Small Condensed v.2.1 file: spac620.tex (ikurtinaitiene) class: spr-small-v1.4 v.2019/10/07 Prn:2019/12/05; $11: 32$ p. 32/42» doctopic: ReviewPaper numbering style: ContentOnly reference style: aps»

A.D. Brown, Microbial Water Stress Physiology. Principles and Perspectives (John Wiley and Sons, Chichester, 1990)

R. Buick, J.S.R. Dunlop, D.I. Groves, Stromatolite recognition in ancient rocks: an appraisal of irregularly laminated structures in an Early Archaean chert-barite unit from North Pole, Western Australia. Alcheringa, Australas. J. Palaeontol. 5(3), 161-181 (1981)

S. Burggraf, H. Fricke, A. Neuner, J. Kristjansson, P. Rouvier, L. Mandelco, C.R. Woese, K.O. Stetter, Methanococcus igneus sp. nov., a novel hyperthermophilic methanogen from a shallow submarine hydrothermal system. Syst. Appl. Microbiol. 13, 263-269 (1990)

D.G. Burns, H.M. Camakaris, P.H. Janssen, M. Dyall-Smith, Cultivation of Walsby's square haloarchaeon. FEMS Microbiol. Lett. 238, 469-473 (2004)

H. Cadillo-Quiroz, J.B. Yavitt, S.H. Zinder, Methanosphaerula palustris gen. nov., sp. nov., a hydrogenotrophic methanogen isolated from a minerotrophic fen peatland. Int. J. Syst. Evol. Microbiol. 59, 928-935 (2009)

A. Camerlenghi, Anoxic basins of the eastern Mediterranean: geological framework. Mar. Chem. 31, 1-19 (1990)

S. Campanaro, A. Vezzi, N. Vitulo, F.M. Lauro M. D’Angelo, F. Simonato, A. Cestaro, G. Malacrida, G. Bertoloni, G. Valle, D.H. Bartlett, Laterally transferred elements and high pressure adaptation in Photobacterium profundum strains. BMC Genomics 14(6), 122 (2005)

D.E. Canfield, M.T. Rosing, C. Bjerrum, Early anaerobic metabolisms. Philos. Trans. R. Soc. Lond. B 361, 1819-1836 (2006)

P. Carini, A. White, E. Campbell, S. Giovannoni, Methane production by phosphate-starved SAR11 chemoheterotrophic marine bacteria. Nat. Commun. 5, 4346 (2014). https://doi.org/10.1038/ncomms5346

A. Cario, M. Jebbar, A. Thiel, N. Kervarec, P. Oger, Molecular chaperone accumulation as a function of stress evidences adaptation to high hydrostatic pressure in the piezophilic archaeon Thermococcus barophilus. Sci. Rep. 6, 29483 (2016)

B. Cavalazzi, R. Barbieri, F. Gómez, B. Capaccioni, K. Olsson-Francis, M. Pondrelli, A.P. Rossi, K. HickmanLewis, A. Agangi, G. Gasparotto, M. Glamoclija, G.G. Ori, N. Rodriguez, M. Hagos, The Dallol geothermal area, Northern Afar (Ethiopia) — an exceptional planetary field analog on Earth. Astrobiology 19, 553-578 (2019)

R. Cavicchioli, Cold-adapted archaea. Nat. Rev. Microbiol. 4, 331-343 (2006)

L. Cheng, T.L. Qiu, X.B. Yin, X.L. Wu, G.Q. Hu, Y. Deng, H. Zhang, Methermicoccus shengliensis gen. nov., sp. nov., a thermophilic, methylotrophic methanogen isolated from oil-production water, and proposal of Methermicoccaceae fam. nov. Int. J. Syst. Evol. Microbiol. 57, 2964-2969 (2007)

S.C. Chong, Y. Liu, M. Cummins, D.L. Valentine, D.R. Boone, Methanogenium marinum sp. nov., a H2using methanogen from Skan Bay, Alaska, and kinetics of H2 utilization. Antonie Van Leeuwenhoek 81, 263-270 (2002)

P.L. Chong, U. Ayesa, V.P. Daswani, E.C. Hur, On physical properties of tetraether lipid membranes: effects of cyclopentane rings. Archaea. 2012, 138439 (2012)

C.E. Cleland, C.F. Chyba, Defining 'life'. Orig. Life Evol. Biosph. 32, 387-393 (2002)

D.R. Colman, S. Poudela, B.W. Stamps, E.S. Boyd, J.R. Spear, The deep, hot biosphere: twenty-five years of retrospection. Proc. Natl. Acad. Sci. 114, 6895-6903 (2017)

F.S. Colwell, S. D'Hondt, Nature and extent of the deep biosphere. Rev. Mineral. Geochem. 75, 547-574 (2013)

J.B. Corliss, J. Dymond, L.I. Gordon, J.M. Edmond, R.P. von Herzen, R.D. Ballard, K. Green, D. Williams, A. Bainbridge, K. Crane, T.H. van Andel, Submarine thermal springs on the Galapagos Rift. Science 203, 1073-1083 (1979)

L. Csonka, Physiological and genetic responses of bacteria to osmotic stress. Microbiol. Rev. 53, 121-147 (1989)

J.C. Cushman, Osmoregulation in plants: implications for agriculture. Am. Zool. 41, 758-769 (2001)

L.E. Cybulski, D. Albanesi, M.C. Mansilla et al., Mechanism of membrane fluidity optimization: isothermal control of the Bacillus subtilis acyl-lipid desaturase. Mol. Microbiol. 45, 1379-1388 (2002)

M.S. da Costa, H. Santos, E.A. Galinski, An overview of the role and diversity of compatible solutes in bacteria and archaea. Adv. Biochem. Biotechnol. 61, 118-153 (1998)

D. Daffonchio, S. Borin, T. Brusa, L. Brusetti, P.W.J.J. van derWielen, H. Bolhuis et al., Stratified prokaryote network in the oxic-anoxic transition of a deep-sea halocline. Nature 440, 203-207 (2006)

C. Dalmasso, P. Oger, G. Selva, D. Courtine, S. L'Haridon, A. Garlaschelli, E. Roussel, J. Miyazaki, J. Reveillaud, M. Jebbar, K. Takai, L. Maignien, K. Alain, Thermococcus piezophilus sp. nov., a novel hyperthermophilic and piezophilic archaeon with a broad pressure range for growth, isolated from a deepest hydrothermal vent at the Mid-Cayman Rise. Syst. Appl. Microbiol. 39(7), 440-444 (2016)

O. Dannenmuller, K. Arakawa, T. Eguchi et al., Membrane properties of archaeal macrocyclic diether phospholipids. Chemistry (Easton) 6, 645-654 (2000) 
«SPAC 11214 layout: Small Condensed v.2.1 file: spac620.tex (ikurtinaitiene) class: spr-small-v1.4 v.2019/10/07 Prn:2019/12/05; $11: 32$ p. 33/42» doctopic: ReviewPaper numbering style: ContentOnly reference style: aps»

Microbial Diversity and Biosignatures: An Icy Moons Perspective

Page 33 of 42

-\#\#\#\#-

1601

1602

1603

1604

1605

1606

1607

1608

1609

1610

1611

1612

1613

1614

1615

1616

A.V. Dass, M. Jaber, A. Brack, F. Foucher, T.P. Kee, T. Georgelin, F. Westall, Potential role of inorganic confined environments in prebiotic phosphorylation. Life 8, 7 (2018)

S. DasSarma, P. Arora, Halophiles. Encyclopedia of Life Sciences (2001). Macmillan Press

M. De Rosa, E. Esposito, A. Gambacorta et al., Complex lipids of Caldariella acidophila, a thermoacidophile archaebacterium. Phytochemistry 19, 821-826 (1980a)

M. De Rosa, E. Esposito, A. Gambacorta et al., Effects of temperature on ether lipid composition of Caldariella acidophila. Phytochemistry 19, 827-831 (1980b)

E.F. DeLong, A.A. Yayanos, Adaptation of the membrane-lipids of a deep-sea bacterium to changes in hydrostatic-pressure. Science 228, 1101-1102 (1985)

A. Dereeper, V. Guignon, G. Blanc, S. Audic, S. Buffet, F. Chevenet, J.F. Dufayard, S. Guindon, V. Lefort, M. Lescot, J.M. Claverie, O. Gascuel, Phylogeny.fr: robust phylogenetic analysis for the non-specialist. Nucleic Acids Res. 36, W465-W469 (2008). (Web Server issue)

D. Desmarais, P.E. Jablonski, N.S. Fedarko, Roberts MF: 2-sulfotrehalose, a novel osmolyte in haloalkaliphilic archaea. J. Bacteriol. 179, 3146-3153 (1997)

D. Dianou, T. Miyaki, S. Asakawa, H. Morii, K. Nagaoka, H. Oyaizu, S. Matsumoto, Methanoculleus chikugoensis sp. nov., a novel methanogenic archaeon isolated from paddy field soil in Japan, and DNA-DNA hybridization among Methanoculleus species. Int. J. Syst. Evol. Microbiol. 51, 1663-1669 (2001)

M.S. Dodd, D. Papineau, T. Grenne, J.F. Slack, M. Rittner, F. Pirajno, J. O'Neil, C.T. Little, Evidence for early life in Earth's oldest hydrothermal vent precipitates. Nature 543, 60-64 (2017)

X. Dong, Z. Chen, Psychrotolerant methanogenic archaea: diversity and cold adaptation mechanisms. Sci. China Life Sci. 55, 415-421 (2012)

E.S. Edgell, Precambrian fossils from the Hamersley Range, Western Australia, and their use in stratigraphic correlation. J. Geol. Soc. Aust. 11, 235-261 (1964)

B. Elazari-Volcani, Genus XII. Halobacterium Elazari-Volcani, 1940, in Bergey's Manual of Determinative Bacteriology, ed. by R.S. Breed, E.G.D. Murray, N.R. Smith 7th edn. (Williams and Wilkins, Baltimore, 1957), pp. 207-212

N. Empadinhas, M.S. da Costa, Diversity and biosynthesis of compatible solutes in hyper/thermophiles. Int. Microbiol. 9, 199-206 (2006)

M. Ernst, H.J. Freisleben, E. Antonopoulos et al., Calorimetry of archaeal tetraether lipid-indication of a novel metastable thermotropic phase in the main phospholipid from Thermoplasma acidophilum cultured at 59 degrees C. Chem. Phys. Lipids 94, 1-12 (1998)

M. Essendoubi, F. Brhada, J.E. Eljamali, A. Filali-Maltouf, S. Bonnassie, S. Georgeault, C. Blanco, M. Jebbar, Osmoadaptative responses in the rhizobia nodulating Acacia isolated from south-eastern Moroccan Sahara. Environ. Microbiol. 9(3), 603-611 (2007)

G. Feller, C. Gerday, Psychrophilic enzymes: hot topics in cold adaptation. Nat. Rev. Microbiol. 1, 200-208 (2003)

V. Formisano, S. Atreya, T. Encrenaz, N. Ignatiev, M. Giuranna, Detection of methane in the atmosphere of Mars. Science 306, 1758-1761 (2004)

P.D. Franzmann, N. Springer, W. Ludwig, E.C. De Macario, M. Rohde, A methanogenic archaeon from Ace Lake, Antarctica: Methanococcoides burtonii sp. nov. Syst. Appl. Microbiol. 15, 573-581 (1992)

P.D. Franzmann, Y. Liu, D.L. Balkwill, H.C. Aldrich, E.C.D. Macario, D.R. Boone, Methanogenium frigidum sp. nov., a psychrophilic, H2-using methanogen from Ace Lake, Antarctica. Int. J. Syst. Bacteriol. 47, 1068-1072 (1997)

E.A. Galinski, H.G. Trüper, Microbial behaviour in salt-stressed ecosystems. FEMS Microbiol. Rev. 15, 95108 (1994)

M.B. Gillett, J.R. Suko, F.O. Santoso, P.H. Yancey, Elevated levels of trimethylamine oxide in muscles of deep-sea gadiform teleosts: a high-pressure adaptation? J. Exp. Zool. 279, 386-391 (1997)

C.R. Glein, J.A. Baross, J. Hunter Waite Jr., The pH of Enceladus' oceans. Geochim. Cosmochim. Acta 162, 202-219 (2015)

A. Gliozzi, R. Rolandi, M. De Rosa, A. Gambacorta, Monolayer black membranes from bipolar lipids of archaebacteria and their temperature-induced structural changes. J. Membr. Biol. 75, 45-56 (1983)

I. Gonthier, M.N. Rager, P. Metzger et al., A di-O-dihydrogeranylgeranyl glycerol from Thermococcus S557, a novel ether lipid, and likely intermediate in the biosynthesis of diethers in Archaea. Tetrahedron Lett. 42, 2795-2797 (2001)

F. Greco, B. Cavalazzi, A. Hofmann, K. Hickman-Lewis, 3.4 Ga biostructures from the barberton greenstone belt of South Africa: new insights into microbial life. Boll. Soc. Paleontol. Ital. 57, 59-74 (2018)

N. Gunde-Cimerman, J. Ramos, A. Plemenitaš, Halotolerant and halophilic fungi. Mycol. Res. 113(11), 1231-1241 (2009)

E. Gunnigle, P. McCay, M. Fuszard, C.H. Botting, F. Abram, V. O’Flaherty, A functional approach to uncover the low-temperature adaptation strategies of the archaeon Methanosarcina barkeri. Appl. Environ. Microbiol. 79, 4210-4219 (2013) 
«SPAC 11214 layout: Small Condensed v.2.1 file: spac620.tex (ikurtinaitiene) class: spr-small-v1.4 v.2019/10/07 Prn:2019/12/05; $11: 32$ p. 34/42» doctopic: ReviewPaper numbering style: ContentOnly reference style: aps»

R.S. Gupta, S. Naushad, S. Baker, Phylogenomic analyse sand molecular signatures for the class Halobacteria and its two major clades: a proposal for division of the class Halobacteria into an emended order Halobacteriales and two new orders, Haloferacales ord. nov. and Natrialbales ord. nov., containing the novel families Haloferacaceae fam. nov. and Natrialbaceae fam. nov. Int. J. Syst. Evol. Microbiol. 65, 1050-1069 (2015)

R.S. Gupta, S. Naushad, R. Fabros, M. Adeolu, A phyloge-nomic reappraisal of family-level divisions within the class Halobacteria: proposal to divide the order Halobacteriales into the families Halobacteriaceae, Haloarculaceae fam. Nov and Halococcaceae fam. nov., and the order Haloferacales into the families, Haloferacaceae and Halorubraceae fam nov. Antonie Van Leeuwenhoek 109, 565-587 (2016)

D. Hafenbradl, M. Keller, R. Thiericke, K.O. Stetter, A novel unsaturated archael ether core lipid from the hyperthermophile Methanopyrus kandleri. Syst. Appl. Microbiol. 16, 165-169 (1993)

J.B.S. Haldane, Origin of life. Ration. Annu. 148, 3-10 (1929)

T. Harding, A.G. Simpson, Recent advances in halophilic protozoa research. J. Eukaryot. Microbiol. 65(4), 556-570 (2018)

T. Hassenkam, M.P. Andersson, K.N. Dalby, D.M.A. Mackenzie, M.T. Rosing, Elements of Eoarchean life trapped in mineral inclusions. Nature 548(3), 78-81 (2017)

R.M. Hazen, D.A. Sverjensky, Mineral surfaces, geochemical complexities, and the origins of life. Cold Spring Harb. Perspect. Biol. 2, a002162 (2010)

R.M. Hazen, N. Boctor, J.A. Brandes, G.D. Cody, R.J. Hemley, A. Sharma, H.S. Yoder Jr., High pressure and the origin of life. J. Phys. Condens. Matter 14, 11489-11494 (2002)

F.F. Hezayen, B.J. Tindall, A. Steinbüchel, B.H.A. Rehm, Characterization of a novel halophilic archaeon, Halobiforma haloterrestris gen. nov., sp. nov., and transfer of Natronobacterium nitratireducens to Halobiforma nitratireducens comb. nov. Int. J. Syst. Evol. Microbiol. 52, 2271-2280 (2002)

K. Hickman-Lewis, R.J. Garwood, M.D. Brasier, T. Goral, H. Jiang, N. McLoughlin, D. Wacey, Carbonaceous microstructures of the 3.46 Ga stratiform 'Apex chert', Chinaman Creek locality, Pilbara, Western Australia. Precambrian Res. 278, 161-178 (2016)

K. Hickman-Lewis, B. Cavalazzi, F. Foucher, F. Westall, Most ancient evidence for life in the Barberton Greenstone Belt: microbial mats and biofabrics of the 23.47 Ga Middle Marker horizon. Precambrian Res. 312, 45-67 (2018)

H.J. Hofmann, A.H. Grey, A.H. Hickman, R.I. Thorpe, Origin of 3.45 Ga coniformstromatolites in Warrawoona Group, Western Australia. Geol. Soc. Am. Bull. 111, 1256-1262 (1999)

G. Holtmann, E. Bremer, Thermoprotection of Bacillus subtilis by exogenously provided glycine betaine and structurally related compatible solutes: Involvement of Opu transporters. J. Bacteriol. 186, 1683-1693 (2004)

C.H. House, D.Z. Oehler, K. Sugitani, K. Mimura, Carbon isotopic analyses of ca. 3.0 Ga microstructures imply planktonic autotrophs inhabited Earth's early oceans. Geology 41(6), 651-654 (2013)

H.W. Hsu, F. Postberg, Y. Sekine, T. Shibuya, S. Kempf, M. Horányi, A. Juhász, N. Altobelli, K. Suzuki, Y. Masaki et al., Ongoing hydrothermal activities within Enceladus. Nature 519, 207-210 (2015)

R. Huber, M. Kurr, H.W. Jannasch, K.O. Stetter, A novel group of abyssal methanogenic archaebacteria (Methanopyrus) growing at 110 C. Nature 342, 833-834 (1989)

T. Iino, H. Tamaki, S. Tamazawa, Y. Ueno, M. Ohkuma, K.i. Suzuki, Y. Igarashi, S. Haruta, Candidatus methanogranum caenicola: a novel methanogen from the anaerobic digested sludge, and proposal of methanomassiliicoccaceae fam. Nov. And methanomassiliicoccales ord. nov., for a methanogenic lineage of the class thermoplasmata. Microbes Environ. 28, 244-250 (2013)

H.W. Jannasch, C.D. Taylor, Deep-sea microbiology. Annu. Rev. Microbiol. 38, 487-514 (1984)

C. Jeanthon, S. L'Haridon, A.L. Reysenbach, M. Vernet, P. Messner, U.B. Sleytr, D. Prieur, Methanococcus infernus sp. nov., a novel hyperthermophilic lithotrophic methanogen isolated from a deep-sea hydrothermal vent. Int. J. Syst. Bacteriol. 4(8 Pt 3), 913-919 (1998)

C. Jeanthon, S. L'Haridon, A.L. Reysenbach, E. Corre, M. Vernet, P. Messner, U.B. Sleytr, D. Prieur, Methanococcus vulcanius sp. nov., a novel hyperthermophilic methanogen isolated from East Pacific Rise, and identification of Methanococcus sp. DSM 4213T as Methanococcus fervens sp. nov. Int. J. Syst. Bacteriol. 49, 583-589 (1999)

M. Jebbar, R. Talibart, K. Gloux, T. Bernard, C. Blanco, Osmoprotection of Escherichia coli by ectoine: uptake and accumulation characteristics. J. Bacteriol. 174(15), 5027-5035 (1992)

M. Jebbar, B. Franzetti, E. Girard, P. Oger, Microbial diversity and adaptation to high hydrostatic pressure in deep-sea hydrothermal vents prokaryotes. Extremophiles 19(4), 721-740 (2015)

B. Jiang, S.N. Parshina, W.V. Doesburg, B.P. Lomans, A.J.M. Stams, Methanomethylovorans thermophila sp. nov., a thermophilic, methylotrophic methanogen from an anaerobic reactor fed with methanol. Int. J. Syst. Evol. Microbiol. 55, 2465-2470 (2005)

W.J. Jones, M.J.B. Paynter, R. Gupta, Characterization of Methanococcus maripaludis sp. nov., a new methanogen isolated from salt marsh sediment. Arch. Microbiol. 135, 91-97 (1983a) 
"SPAC 11214 layout: Small Condensed v.2.1 file: spac620.tex (ikurtinaitiene) class: spr-small-v1.4 v.2019/10/07 Prn:2019/12/05; $11: 32$ p. 35/42» doctopic: ReviewPaper numbering style: ContentOnly reference style: aps»

Microbial Diversity and Biosignatures: An Icy Moons Perspective

Page 35 of 42

-\#\#\#\#-

W.J. Jones, J.A. Leigh, F. Mayer, C.R. Woese, R.S. Wolfe, Methanococcus jannaschii sp. nov., an extremely thermophilic methanogen from a submarine hydrothermal vent. Arch. Microbiol. 136, 254-261 (1983b)

M. Kamekura, Diversity of extremely halophilic bacteria. Extremophiles 2, 289-295 (1998)

M. Kamekura, M.L. Dyall-Smith, Taxonomy of the family Halobacteriaceae and the description of two new genera Halorubrobacterium and Natrialba. J. Gen. Appl. Microbiol. 41, 333-350 (1995)

M. Kamekura, M.L. Dyall-Smith, V. Upasani, A. Ventosa, M. Kates, Diversity of alkaliphilic halobacteria: proposals for transfer of Natronobacterium vacuolatum, Natronobacterium magadii, and Natronobacterium pharaonic to Halorubrum, Natrialba, and Natronomonas gen. nov., respectively, as Halorubrum vacuolatum comb. nov., Natrialba magadii comb. nov., and Natronomonas pharaonic comb. nov., respectively. Int. J. Syst. Bacteriol. 47, 853-857 (1997)

D.M. Karl, L. Beversdorf, K. Björkman, M.J. Church, A. Martinez, E.F. Delong, Aerobic production of methane in the sea. Nat. Geosci. 1, 473-478 (2008)

R. Kasahara, T. Sato, H. Tamegai, K.C. Piezo-adapted, 3-isopropylmalate dehydrogenase of the obligate piezophile Shewanella benthica DB21MT-2 isolated from the 11,000-m depth of the Mariana Trench. Biosci. Biotechnol. Biochem. 73(11), 2541-2543 (2009)

R. Kasai, Y. Kitajima, C.E. Martin et al., Molecular control of membrane properties during temperature acclimatation-membrane fluidity regulation of fatty acid desaturase action. Biochemistry 15, 52285233 (1976)

R.H. Kelly, P.H. Yancey, High contents of trimethylamine oxide correlating with depth in deep-sea teleost fishes, skates, and decapod crustaceans. Biol. Bull. 196, 18-25 (1999)

B. Kempf, E. Bremer, Uptake and synthesis of compatible solutes as microbial stress responses to highosmolality environments. Arch. Microbiol. 170(5), 319-330 (1998)

A.H. Knoll, M.A. Nowak, The timetable of evolution. Sci. Adv. 3, e1603076 (2017)

A.H. Knoll, K. Bergmann, J.V. Strauss, J.V. Life, The first two billion years. Philos. Trans. R. Soc. Lond. B, Biol. Sci. 371, 20150493 (2016)

C. Koeberl, The record of impact processes on the early Earth-a review of the first 2.5 billion years, in Processes of the Early Earth, Geological Society of America Special Paper 405, ed. by W.U. Reimold, R.L. Gibson. (Geological Society of America, Boulder, 2006), pp. 1-22

Y. Koga, Thermal adaptation of the archaeal and bacterial lipid membranes. Archaea (Vanc. B. C.) 2012, 789652 (2012)

T. Kozawa, K. Sugitani, D.Z. Oehler, C.H. House, I. Saito, T. Watanabe, G.T. Early, Archean planktonic mode of life: Implications from fluid dynamics of lenticular microfossils. Geobiol., 17 (2018)

T.A. Kral, S.T. Altheide, Methanogen survival following exposure to desiccation, low pressure and martian regolith analogs. Planet. Space Sci. 89, 167-171 (2013)

T.A. Kral, T.S. Altheide, A.E. Lueders, A.C. Schuerger, Low pressure and desiccation effects on methanogens: implications for life on Mars. Planet. Space Sci. 59, 264-270 (2011)

A.U. Kuhlmann, J. Bursy, S. Gimpel, T. Hoffmann, E. Bremer, Synthesis of the compatible solute ectoine in Virgibacillus pantothenticus is triggered by high salinity and low growth temperature. Appl. Environ. Microbiol. 74, 4560-4563 (2008)

H.J. Kunte, H.G. Trüper, S.-L.H. Halophilic, Microorganisms, in Astrobiology, ed. by G. Horneck, C. Baumstark-Khan (Springer, Berlin, 2002)

M.C. Lai, K.R. Sowers, D.E. Robertson, M.F. Roberts, R.P. Gunsalus, Distribution of compatible solutes in the halophilic methanogenic archaebacteria. J. Bacteriol. 173, 5352-5358 (1991)

M.C. Lai, T.Y. Hong, R.P. Gunsalus, Glycine betaine transport in the obligate halophilic archaeon Methanohalophilus portucalensis. J. Bacteriol. 182, 5020-5024 (2000)

D. Lai, J.R. Springstead, H.G. Monbouquette, Effect of growth temperature on ether lipid biochemistry in Archaeoglobus fulgidus. Extremophiles 12, 271-278 (2008)

N. Lane, W.F. Martin, The origin of membrane energetics. Cell 151, 1406-1416 (2012)

F.M. Lauro, K. Tran, A. Vezzi, N. Vitulo, G. Valle, B.DH. Large-Scale, Transposon mutagenesis of Photobacterium profundum SS9 reveals new genetic loci important for growth at low temperature and high pressure. J. Bacteriol. 190, 1699-1709 (2008)

A.G. Lee, Lipid-protein interactions in biological membranes: a structural perspective. Biochim. Biophys. Acta 1612, 1-40 (2003)

A.G. Lee, How lipids affect the activities of integral membrane proteins. Biochim. Biophys. Acta, Biomembr. 1666, 62-87 (2004)

S. L'Haridon, A.L. Reysenbach, A. Banta, P. Messner, P. Schumann, E. Stackebrandt, C. Jeanthon, Methanocaldococcus indicus sp. nov., a novel hyperthermophilic methanogen isolated from the Central Indian Ridge. Int. J. Syst. Evol. Microbiol. 53, 1931-1935 (2003)

J. Lim, T. Thomas, R. Cavicchioli, Low temperature regulated DEAD-box RNA helicase from the antarctic archaeon, Methanococcoides burtonii. J. Mol. Biol. 297, 553-567 (2000) 
"SPAC 11214 layout: Small Condensed v.2.1 file: spac620.tex (ikurtinaitiene) class: spr-small-v1.4 v.2019/10/07 Prn:2019/12/05; $11: 32$ p. 36/42» doctopic: ReviewPaper numbering style: ContentOnly reference style: aps»

J.F. Lindsay, M.D. Brasier, N. McLoughlin, O.R. Green, M. Fogel, A. Steele, S.A. Mertzman, The problem of deepcarbon-an Archean paradox. Precambrian Res. 143, 1-22 (2005)

Y. Liu, W.B. Whitman, Metabolic, phylogenetic, and ecological diversity of the methanogenic archaea. Ann. N.Y. Acad. Sci. 1125, 171-189 (2008)

D.R. Lowe, Abiological origin of described stromatolites older than 3.2 Ga. Geology 22, 387-390 (1994)

D.R. Lowe, G.R. Byerly, Geologic record of partial ocean evaporation triggered by giant asteroid impacts, 3.29-3.23 billion years ago. Geology 43, 6 (2015)

D.R. Lowe, G.R. Byerly, F.T. Kyte, Recently discovered 3.42-3.23 Ga impact layers, Barberton Belt, South Africa: 3.8 Ga detrital zircons, Archean impact history, and tectonic implications. Geology 42, 747-750 (2014)

Z. Lü, Y. Lu, Methanocella conradii sp. nov., a thermophilic, obligate hydrogenotrophic methanogen, isolated from Chinese rice field soil. PLoS ONE 7, e35279 (2012)

K. Ma, X. Liu, X. Dong, Methanosaeta harundinacea sp. nov., a novel acetate-scavenging methanogen isolated from a UASB reactor. Int. J. Syst. Evol. Microbiol. 56, 127-131 (2006)

A.M. Macgregor, A pre-Cambrian algal limestone in Southern Rhodesia. Trans. Geol. Soc. S. Afr. 43, 9-15 (1940)

G.M. Maestrojuán, D.R. Boone, L. Xun, R.A. Mah, L. Zhang, Transfer of Methanogenium bourgense, Methanogenium marisnigri, Methanogenium olentangyi, and Methanogenium thermophilicum to the Genus Methanoculleus gen. nov., Emendation of Methanoculleus marisnigri and Methanogenium, and Description of New Strains of Methanoculleus bourgense and Methanoculleus marisnigri. Int. J. Syst. Bacteriol. 40, 117-122 (1990)

C. Magnabosco, L. Lin, H. Dong, M. Bomberg, W. Ghiorse, H. Stan-Lotter, K. Pedersen, T.L. Kieft, E. van Heerden, T.C. Onstott, The biomass and biodiversity of the continental subsurface. Nat. Geosci. 11, 707-717 (2018)

K. Mangelsdorf, K.G. Zink, J.L. Birrien, L. Toffin, A quantitative assessment of pressure dependent adaptive changes in the membrane lipids of piezosensitive deep sub-seafloor bacterium. Org. Geochem. 36, 14591479 (2005)

A.G. Marr, J.L. Ingraham, Effect of temperature on the composition of fatty acids in Escherichia coli. J. Bacteriol. 84, 1260-1267 (1962)

W. Martin, M.J. Russell, On the origins of cells: a hypothesis for the evolutionary transitions from abioitic geochemistry to chemoautotrophic prokaryotes, and fromprokaryotes to nucleated cells. Philos. Trans. R. Soc. Lond. B, Biol. Sci. 358, 59-85 (2003)

W. Martin, M.J. Russell, On the origins of cells: a hypothesis for the evolutionary transitions from abiotic geochemistry to chemoautotrophic prokaryotes, and from prokaryotes to nucleated cells. Philos. Trans. R. Soc. Lond. B, Biol. Sci. 358, 59 (2003)

W. Martin, M.J. Russell, On the origin of biochemistryat an alkaline hydrothermal vent. Philos. Trans. R. Soc. Lond. B, Biol. Sci. 362, 1887-1926 (2007)

D.D. Martin, D.H. Bartlett, M.F. Roberts, Solute accumulation in the deep-sea bacterium Photobacterium profundum. Extremophiles 6, 507-514 (2002)

W. Martin, J. Baross, D. Kelley, M.J. Russell, Hydrothermal vents and the origin of life. Nat. Rev. Microbiol. 6, 805-814 (2008)

J.C. Mathai, G.D. Sprott, M.L. Zeidel, Molecular mechanisms of water and solute transport across archaebacterial lipid membranes. J. Biol. Chem. 276, 27266-27271 (2001)

Y. Matsuno, A. Sugai, H. Higashibata et al., Effect of growth temperature and growth phase on the lipid composition of the archaeal membrane from Thermococcus kodakaraensis. Biosci. Biotechnol. Biochem. 73, 104-108 (2009)

T.J. McGenity, W.D. Grant, Transfer of Halobacterium sacchurovorum, Hulobacterium sodomense, Halobacterium trupanicum NRC34021 and Halobacterium lucusprofundi to the genus Halorubrum gen. nov., as Halorubmm saccharovorurn comb. nov., Halorubrum sodomense comb. nov., Halorubnun trupanicum comb. nov., and Halonibrum lacusprofundi comb. nov. Syst. Appl. Microbiol. 18, 237-243 (1995)

T.J. McGenity, R.T. Gemmell, W.D. Grant, Proposal of a new halobacterial genus Natrinema gen. nov., with two species Natrinema pellirubrumnom. nov., and Natrinema pallidumnom. nov. Int. J. Syst. Bacteriol. 48, 1187-1196 (1998)

C.P. McKay, C.C. Porco, T. Altheide, W.L. Davis, T.A. Kral, The possible origin and persistence of life on Enceladus and detection of biomarkers in the plume. Astrobiology 8, 909-919 (2008)

C.P. McKay, B.N. Khare, R. Amin, M. Klasson, T.A. Kral, Possible sources for methane and C2-C5 organics in the plume of Enceladus. Planet. Space Sci. 71, 73-79 (2012)

W.W. Metcalf, B.M. Griffin, R.M. Cicchillo, J. Gao, S.C. Janga, H.A. Cooke, B.T. Circello, B.S. Evans, W. Martens-Habbena, D.A. Stahl et al., Synthesis of methylphosphonic acid by marine microbes: a source for methane in the Aerobic ocean. Science 337, 1104-1107 (2012) 
"SPAC 11214 layout: Small Condensed v.2.1 file: spac620.tex (ikurtinaitiene) class: spr-small-v1.4 v.2019/10/07 Prn:2019/12/05; $11: 32$ p. 37/42» doctopic: ReviewPaper numbering style: ContentOnly reference style: aps»

Microbial Diversity and Biosignatures: An Icy Moons Perspective

Page 37 of 42

_\#\#\#\#_

1801

1802

1803

1804

1805

1806

1807

1808

1809

1810

1811

1812

1813

1814

1815

1816

1817

1818

1819

1820

1821

1822

1823

1824

1825

1826

1827

S.L. Miller, A production of amino acids under possible primitive Earth conditions. Science 117, 528-529 (1953)

J.F. Miller, N.N. Shah, C.M. Nelson, J.M. Ludlow, D.S. Clark, Pressure and temperature effects on growth and methane production of the extreme thermophile Methanococcus jannaschii. Appl. Environ. Microbiol. 54, 3039-3042 (1988)

R. Mondav, B.J. Woodcroft, E.H. Kim, C.K. McCalley, S.B. Hodgkins, P.M. Crill, J. Chanton, G.B. Hurst, N.C. VerBerkmoes, S.R. Saleska et al., Discovery of a novel methanogen prevalent in thawing permafrost. Nat. Commun. 5, 3212 (2014). https://doi.org/10.1038/ncomms4212

R. Montalvo-Rodríguez, R.H. Vreeland, A. Oren, M. Kessel, C. Betancourt, J. López-Garriga, Halogeometricum borinquense, gen. nov., sp. nov., a novel halophilic archaeon from Puerto Rico. Int. J. Syst. Bacteriol. 48, 1305-1312 (1998)

J.M. Moore, C.R. Chapman, E.B. Bierhaus, R. Greeley, F.C. Chuang, J. Klemaszewski, R.N. Clark, J.B. Dalton, C.A. Hibbitts, P.M. Schenk, et al., Callisto, in Jupiter. The Planet, Satellites and Magnetosphere, ed. by F. Bagenal, T.E. Dowling, W.B. McKinnon (Cambridge University Press, Cambridge, 2004), pp. 397-426

E.K. Moore, B.I. Jelen, D. Giovannelli, H. Raanan, P.G. Falkowski, Metal availability and the expanding network of microbial metabolisms in the Archaean eon. Nat. Geosci. 10, 629-636 (2017)

D. Morozova, D. Wagner, Stress response of methanogenic archaea from Siberian permafrost compared with methanogens from nonpermafrost habitats. FEMS Microbiol. Ecol. 61, 16-25 (2007)

M.J. Mumma, G.L. Villanueva, R.E. Novak, T. Hewagama, B.P. Bonev, M.A. DiSanti, A.M. Mandell, M.D. Smith, Strong release of methane on Mars in northern summer 2003. Science 323, 1041-1045 (2009)

C. Neves, M.S. da Costa, H. Santos, Compatible solutes of the hyperthermophile Palaeococcus ferrophilus: osmoadaptation and thermoadaptation in the order thermococcales. Appl. Environ. Microbiol. 71, 80918098 (2005)

D.S. Nichols, M.R. Miller, N.W. Davies, A. Goodchild, M. Raftery, R. Cavicchioli, Cold adaptation in the Antarctic Archaeon Methanococcoides burtonii involves membrane lipid unsaturation. J. Bacteriol. 186, $8508-8515$ (2004)

P. Nielsen, D. Fritze, F.G. Priest, Phenetic diversity of alkaliphilic Bacillus strains: proposal for nine new species. Microbiology 141, 1745-1761 (1995)

H.B. Niemann, S.K. Atreya, S.J. Bauer, G.R. Carignan, J.E. Demick, R.L. Frost, D. Gautier, J.A. Haberman, D.N. Harpold, D.M. Hunten et al., The abundances of constituents of Titan's atmosphere from the GCMS instrument on the Huygens probe. Nature 438, 779-784 (2005)

E.G. Nisbet, C.M.R. Fowler, Archaean metabolic evolution of microbial mats. Proc. R. Soc. Lond. B, Biol. Sci. 266, 2375-2382 (1999)

N. Nishimura, S. Kitaura, A. Mimura, Y. Takahara, Cultivation of thermophilic methanogen KN-15 on H2CO2 under pressurized conditions. J. Ferment. Bioeng. 73, 477-480 (1992)

A.P. Nutman, V.C. Bennett, C.R.L. Friend, M.J. Van Kranendonk, A.R. Chivas, Rapid emergence of life shown by discovery of 3,700-million-year-old microbial structures. Nature 537, 535-538 (2016)

D.Z. Oehler, M.M. Walsh, K. Sugitani, M.-C. Liu, C.H. House, Large and robust lenticular microorganisms on the young Earth. Precambrian Res. 296, 112-119 (2017)

P.M. Oger, A. Cario, Adaptation of the membrane in Archaea. Biophys. Chem. 183, 42-56 (2013)

P. Oger, M. Jebbar, The many ways of coping with pressure. Res. Microbiol. 161, 799-809 (2010)

B. Ollivier, P. Caumette, J.-L. Garcia, R.A. Mah, Anaerobic bacteria from hypersaline environments. Microbiol. Rev. 58, 27-38 (1994)

A.I. Oparin, Proiskhozhdenic Zhizny (Izd. Moskovski Rabochii, Moscow, 1924)

A. Oren, Bioenergetic aspects of halophilism. Microbiol. Mol. Biol. Rev. 63, 334-348 (1999)

A. Oren, Diversity of halophilic microorganisms: environments, phylogeny, physiology, and applications. J. Ind. Microbiol. Biotech. 28, 56-63 (2002a)

A. Oren, Molecular ecology of extremely halophilic archaea and bacteria. FEMS Microbiol. Ecol. 39, 1-7 (2002b)

A. Oren, Convergent evolution in extremely halophilic prokaryotes: a comparison between Salinibacter ruber (Bacteria) and the Halobacteriaceae (Archaea), in Evolutionary Theory and Processes: Modern Horizons. Papers in Honour of Eviatar Nevo, ed. by S.P. Wasser (Kluwer Academic Publishers, Dordrecht, 2004), pp. 53-64

A. Oren, The family methanosarcinaceae, in The Prokaryotes, ed. by E. Rosenberg, E.F. DeLong, S. Lory, E. Stackebrandt, F. Thompson (Springer, Berlin, 2014)

A. Oren, P. Gurevich, R.T. Gemmell, A. Teske, Halobaculum gomorrense gen. nov., sp. nov., a novel extremelyhalophilic archaeon from the Dead Sea. Int. J. Syst. Bacteriol. 45, 747-754 (1995)

A. Oren, The order Halobacteriales, in The Prokaryotes: Anevolving Electronic Resource for the Microbiological Community [Online], ed. by M. Dworkin et al. 3rd edn. (Springer, New York, 2000)

$<$ uncited $>$ 
A. Oren, R. Elevi, S. Watanabe, K. Ihara, A. Corcelli, Halomicrobium mukohataei gen. nov., comb. nov., and emended description of Halomicrobium mukohataei. Int. J. Syst. Evol. Microbiol. 52, 1831-1835 (2002)

P. Pappenreiter, S. Zwirtmayr, L.-M. Mauerhofer, S.K.-M.R. Rittmann, C. Paulik, Development of a simultaneous bioreactor system for characterization of gas production kinetics of methanogenic archaea at high pressure. Eng. Life Sci. 19, 537-544 (2019)

C.B. Park, D.S. Clark, Rupture of the cell envelope by decompression of the deep-sea methanogen Methanococcus jannaschii. Appl. Environ. Microbiol. 68, 1458-1463 (2002)

S.N. Parshina, A.V. Ermakova, M. Bomberg, E.N. Detkova, Methanospirillum stamsii sp. nov., a psychrotolerant, hydrogenotrophic, methanogenic archaeon isolated from an anaerobic expanded granular sludge bed bioreactor operated at low temperature. Int. J. Syst. Evol. Microbiol. 64, 180-186 (2014)

B.K.D. Pearce, A.S. Tupper, R.E. Pudritz, P.G. Higgs, Constraining the time interval for the origin of life on Earth. Astrobiology 18(3), 343-364 (2018)

A.P. Petroff, M.S. Sim, A. Maslov, M. Krupenin, D.H. Rothman, T. Bosak, Biophysical basis for the geometry of conical stromatolites. Proc. Natl. Acad. Sci. USA 107, 9956-9961 (2010)

A.P. Petroff, N.J. Beukes, D.H. Rothman, T. Bosak, Biofilm growth and fossil form. Phys. Rev. X 3, 014012 (2013)

B. Poolman, E. Glaasker, Regulation of compatible solute accumulation in bacteria. Mol. Microbiol. 29, 397-407 (1998)

L.M. Proctor, R. Lai, R.P. Gunsalus, The methanogenic archaeon Methanosarcina thermophila TM-1 possesses a high-affinity glycine betaine transporter involved in osmotic adaptation. Appl. Environ. Microbiol. 63, 2252-2257 (1997)

C. Quast, E. Pruesse, P. Yilmaz, J. Gerken, T. Schweer, P. Yarza, J. Peplies, F.O. Glöckner, The SILVA ribosomal RNA gene database project: improved data processing and web-based tools. Nucleic Acids Res. 41, 590-596 (2013)

S. Rea, J.P. Bowman, S. Popovski, C. Pimm, A.D.G. Wright, Methanobrevibacter millerae sp. nov. and Methanobrevibacter olleyae sp. nov., methanogens from the ovine and bovine rumen that can utilize formate for growth. Int. J. Syst. Evol. Microbiol. 57, 450-456 (2007)

F. Reith, Life in the deep subsurface. Geology 39, 287-288 (2011)

R. Riding, Microbialites, stromatolites, and thrombolites, in Encyclopaedia of Geobiology (Encyclopaedia of Earth Sciences Series), ed. by V. Reitner, J. Thiel (Springer, Heidelberg, 2011), pp. 635-654

S. Rittmann, A. Seifert, C. Herwig, Essential prerequisites for successful bioprocess development of biological $\mathrm{CH} 4$ production from CO2 and H2. Crit. Rev. Biotechnol. 35, 141-151 (2015)

D.E. Robertson, D. Noll, M.F. Roberts, J.A. Menaia, D.R. Boone, Detection of the osmoregulator betaine in methanogens. Appl. Environ. Microbiol. 56, 563-565 (1990)

F. Rodríguez-Valera, Characteristics and microbial ecology of hyper-saline environments, in Halophilicbacteria, vol. 1, ed. by F. Rodriguez-Valera (CRC Press, Inc., Boca Raton, 1988), pp. 3-30

M. Roeßler, K. Pflüger, H. Flach, T. Lienard, G. Gottschalk, V. Müller, Identification of a salt-induced primary transporter for glycine betaine in the methanogen Methanosarcina mazei Gö1. Appl. Environ. Microbiol. 68, 2133-2139 (2002)

L.A. Romanenko, N. Tanaka, G.M. Frolova, V.V. Mikhailov, Psychrobacter fulvigenes sp. nov., isolated from a marine crustacean from the Sea of Japan. Int. J. Syst. Evol. Microbiol. 59(Pt 6), 1480-6 (2009)

J.A. Romesser, R.S. Wolfe, F. Mayer, E. Spiess, A. Walther-Mauruschat, Methanogenium, a new genus of marine methanogenic bacteria, and characterization of Methanogenium cariaci sp. nov. and Methanogenium marisnigri sp. nov. Arch. Microbiol. 121, 147-153 (1979)

M.T. Rosing, C-13-depleted carbon microparticles in > 3700-Ma sea-floor sedimentary rocks from west Greenland. Science 283, 674-676 (1999)

N.J. Russell, D.S. Nichols, Polyunsaturated fatty acids in marine bacteria-a dogma rewritten. Microbiology 145(Pt 4), 767-779 (1999)

M.J. Russell, A.J. Hall, W. Martin, Serpentinization as a source of energy at the origin of life. Geobiology 8 , 355-371 (2010)

N.F.W. Saunders, T. Thomas, P.M.G. Curmi, J.S. Mattick, E. Kuczek, R. Slade, J. Davis, P.D. Franzmann, D. Boone, K. Rusterholtz et al., Mechanisms of thermal adaptation revealed from the genomes of the Antarctic archaea methanogenium frigidum and Methanococcoides burtonii. Genome Res. 13, 15801588 (2003)

J. Schirmack, K. Mangelsdorf, L. Ganzert, W. Sand, A. Hillebrand-Voiculescu, D. Wagner, Methanobacterium movilense sp. nov., a hydrogenotrophic, secondary-alcohol-utilizing methanogen from the anoxic sediment of a subsurface lake. Int. J. Syst. Evol. Microbiol. 64, 522-527 (2014)

C. Schleper, G. Puehler, I. Holz, A. Gambacorta, D. Janekovic, U. Santarius, H.P. Klenk, W. Zillig, Picrophilus gen. nov., fam. nov.: a novel aerobic, heterotrophic, thermoacidophilic genus and family comprising archaea capable of growth around pH 0. J. Bacteriol. 177(24), 7050-7059 (1995) 
«SPAC 11214 layout: Small Condensed v.2.1 file: spac620.tex (ikurtinaitiene) class: spr-small-v1.4 v.2019/10/07 Prn:2019/12/05; $11: 32$ p. 39/42» doctopic: ReviewPaper numbering style: ContentOnly reference style: aps»

Microbial Diversity and Biosignatures: An Icy Moons Perspective

Page 39 of 42

-\#\#\#\#-

1901

1902

1903

1904

1905

1906

1907

1908

1909

1910

1911

1912

1913

1914

1915

1916

1917

1918

1919

1920

1921

1922

1923

1924

1925

1926

1927

1928

G. Schoop, Obligat halophile Mikroben. Zentr Bakteriol Parasitenk Orig, Abt I. (1935), pp. 14-23

A.H. Seifert, S. Rittmann, S. Bernacchi, C. Herwig, Method for assessing the impact of emission gasses on physiology and productivity in biological methanogenesis. Bioresour. Technol. 136, 747-751 (2013)

A.H. Seifert, S. Rittmann, C. Herwig, Analysis of process related factors to increase volumetric productivity and quality of biomethane with Methanothermobacter marburgensis. Appl. Energy 132, 155-162 (2014)

H. Shimada, N. Nemoto, Y. Shida et al., Effects of $\mathrm{pH}$ and temperature on the composition of polar lipids in Thermoplasma acidophilum HO-62. J. Bacteriol. 190, 5404-5411 (2008)

K.S. Siddiqui, R. Cavicchioli, Cold-adapted enzymes. Annu. Rev. Biochem. 75, 403-433 (2006)

K. Siddiqui, R. Cavicchioli, T. Thomas, Thermodynamic activation properties of elongation factor 2 (EF-2) proteins from psychrotolerant and thermophilic Archaea. Extremophiles 6, 143-150 (2002)

M.V. Simankova, S.N. Parshina, T.P. Tourova, T.V. Kolganova, A.J. Zehnder, A.N. Nozhevnikova, Methanosarcina lacustris sp. nov., a new psychrotolerant methanogenic archaeon from anoxic lake sediments. Syst. Appl. Microbiol. 24, 362-367 (2001)

M. Sinensky, Temperature control of phospholipid biosynthesis in Escherichia coli. J. Bacteriol. 106, 449455 (1971)

M. Sinensky, Homeoviscous adaptation-homerostatic process that regulates viscosity of membrane lipids in Escherichia coli. Proc. Natl. Acad. Sci. USA 71, 522-525 (1974)

N. Singh, M.M. Kendall, Y. Liu, D.R. Boone, Isolation and characterization of methylotrophic methanogens from anoxic marine sediments in Skan Bay, Alaska: description of Methanococcoides alaskense sp. nov., and emended description of Methanosarcina baltica. Int. J. Syst. Evol. Microbiol. 55, 2531-2538 (2005)

N.H. Sleep, Geological and geochemical constraints on the origin and evolution of life. Astrobiology 18, 1199-1219 (2018)

D.Y. Sorokin, B. Abbas, A.Y. Merkel, W.I. Rijpstra, J.S. Damsté, M.V. Sukhacheva, M.C. van Loosdrecht, Methanosalsum natronophilum sp. nov., and Methanocalculus alkaliphilus sp. nov., haloalkaliphilic methanogens from hypersaline soda lakes. Int. J. Syst. Evol. Microbiol. 65(10), 3739-3745 (2015)

D.Y. Sorokin, A.Y. Merkel, B. Abbas, K.S. Makarova, W.I.C. Rijpstra, M. Koenen, J.S. Sinninghe Damsté, E.A. Galinski, E.V. Koonin, M.C.M. van Loosdrecht, Methanonatronarchaeum thermophilum gen. nov., sp. nov. and 'Candidatus Methanohalarchaeum thermophilum', extremely halo(natrono)philic methylreducing methanogens from hypersaline lakes comprising a new euryarchaeal class Methanonatronarchaeia classis nov. Int. J. Syst. Evol. Microbiol. 68(7), 2199-2208 (2018)

K.R. Sowers, J.E. Boone, R.P. Gunsalus, Disaggregation of Methanosarcina spp. and growth as single cells at elevated osmolarity. Appl. Environ. Microbiol. 59, 3832-3839 (1993)

G.D. Sprott, M. Meloche, J.C. Richards, Proportions of diether, macrocyclic diether, and tetraether lipids in Methanococcus jannaschii grown at different temperatures. J. Bacteriol. 173, 3907-3910 (1991)

L.C. Stewart, M. Kates, I.H. Ekiel, I.CP. Smith, Molecular order and dynamics of diphytanylglycerol phospholipids - a 2H NMR and 31P NMR study. Chem. Phys. Lipids 54, 115-129 (1990)

K. Sugitani, Early Archaean (pre-3.0 Ga) cellularly preserved microfossils and microfossil-like structures frm the Pilbara craton, Western Australia-a review, in Earth's Oldest Rocks, ed. by M.J. Van Kranendonk, V.C. Bennett, J.E. Hofmann 2nd edn. (2018), pp. 1007-1028

K. Sugitani, K. Grey, A. Allwood, T. Nagaoka, K. Mimura, M. Minami, C.P. Marshall, M.J. Van Kranendonk, M.R. Walter, Diverse microstructures from Archaean chert from the mount goldsworthy-mount grant area, pilbara craton, western Australia: microfossils, dubiofossils, or pseudofossils? Precambrian Res. 158, 228-262 (2007)

K. Sugitani, K. Mimura, M. Takeuchi, T. Yamaguchi, K. Suzuki, R. Senda, Y. Asahara, S. Wallis, M.J. Van Kranendonk, A Paleoarchean coastal hydrothermal field inhabited by diverse microbial communities: the Strelley Pool Formation, Pilbara Craton Western Australia. Geobiology 13, 522-545 (2015)

W. Sunda, D.J. Kieber, R.P. Kiene, S. Huntsman, An antioxidant function for DMSP in marine algae. Nature 418, 317-320 (2002)

K. Takai, A. Inoue, K. Horikoshi, Methanothermococcus okinawensis sp. nov., a thermophilic, methaneproducing archaeon isolated from a Western Pacific deep-sea hydrothermal vent system. Int. J. Syst. Evol. Microbiol. 52, 1089-1095 (2002)

K. Takai, K. Nakamura, T. Toki, U. Tsunogai, M. Miyazaki, J. Miyazaki, H. Hirayama, S. Nakagawa, T. Nunoura, K. Horikoshi, Cell proliferation at 122 degrees $\mathrm{C}$ and isotopically heavy $\mathrm{CH} 4$ production by a hyperthermophilic methanogen under high-pressure cultivation. Proc. Natl. Acad. Sci. USA 105, 10949-10954 (2008)

H. Tamegai, L. Li, N. Masui, C. Kato, A denitrifying bacterium from the deep sea at 11,000-m depth. Extremophiles 1997(1), 207-211 (1997)

T. Tashiro, A. Ishida, M. Hori, M. Igisu, M. Koike, P. Méjean, N. Takahata, Y. Sano, T. Komiya, Early trace of life from 3.95 Ga sedimentary rocks in Labrador, Canada. Nature 549, 516-518 (2017) 
«SPAC 11214 layout: Small Condensed v.2.1 file: spac620.tex (ikurtinaitiene) class: spr-small-v1.4 v.2019/10/07 Prn:2019/12/05; $11: 32$ p. 40/42» doctopic: ReviewPaper numbering style: ContentOnly reference style: aps»

R.-S. Taubner, J. Leitner, M. Firneis, R. Hitzenberger, Modelling the Interior Structure of Enceladus Based on the 2014's Cassini Gravity Data. J. Orig. Life Evol. Biosph., 1-6 (2015)

R.-S. Taubner, P. Pappenreiter, J. Zwicker, D. Smrzka, C. Pruckner, P. Kolar, S. Bernacchi, A.H. Seifert, A. Krajete, W. Bach, J. Peckmann, C. Paulik, M.G. Firneis, C. Schleper, S.K.-M.R. Rittmann, Biological methane production under putative Enceladus-like conditions. Nat. Commun. 9, 748 (2018). https://doi.org/10.1038/s41467-018-02876-y

R.-S. Taubner, L.M.F. Baumann, T. Bauersachs, E.L. Clifford, B. Mähnert, B. Reischl, R. Seifert, J. Peckmann, S.K.-M.R. Rittmann, D. Birgel, Membrane lipid composition and amino acid excretion patterns of Methanothermococcus okinawensis grown in the presence of inhibitors detected in the Enceladian plume (under review)

R.-S. Taubner, S. Rittmann, J. Leitner, C. Schleper, M. Firneis, R. Hitzenberger, Assessing the feasibility to cultivate methanogens under Enceladus-like conditions reservoir. Presented at the 14th European Workshop on Astrobiology, Edinburgh, UK, 13-16 October 2014

R.K. Thauer, A.K. Kaster, H. Seedorf, W. Buckel, R. Hedderich, Methanogenic archaea: ecologically relevant differences in energy conservation. Nat. Rev. Microbiol. 6, 579-591 (2008)

T. Thomas, R. Cavicchioli, Effect of temperature on stability and activity of elongation factor 2 proteins from Antarctic and thermophilic methanogens. J. Bacteriol. 182, 1328-1332 (2000)

T. Thomas, N. Kumar, R. Cavicchioli, Effects of ribosomes and intracellular solutes on activities and stabilities of elongation factor 2 proteins from psychrotolerant and thermophilic methanogens. J. Bacteriol. 183, 1974-1982 (2001)

M.M. Tice, Environmental controls on photosynthetic microbial mat distribution and 728 morphogenesis on a 3.42 Ga clastic-starved platform. Astrobiology 9, 989-1000 (2009)

M.M. Tice, D.R. Lowe, Photosynthesis microbial mats in the 3.416-Myr-old ocean. Nature 431, 549-552 (2004)

B.J. Tindall, H.N.M. Ross, W.D. Grant, Natronobacterium gen. nov., and Natronococcus gen. nov., two new genera of haloalkaliphilic archaebacteria. Syst. Appl. Microbiol. 5, 41-57 (1984)

M. Torreblanca, F. Rodriguez-Valera, G. Juez, A. Ventosa, M. Kamekura, M. Kates, Classification of nonalkaliphilic halobacteria based onnumerical taxonomy and polar lipid composition, and description of Halo-arculagen nov. and Haloferaxgen. nov. Syst. Appl. Microbiol. 8, 89-99 (1986)

E.J. Trower, D.R. Lowe, Sedimentology of the $~ 3.3$ Ga upper Mendon Formation, Barberton Greenstone Belt, South Africa. Precambrian Res. 281, 473-494 (2016)

I. Uda, A. Sugai, Y.H. Itoh, T. Itoh, Variation in molecular species of polar lipids from Thermoplasma acidophilum depends on growth temperature. Lipids 36, 103-105 (2001)

Y. Uda, A. Sugai, Y.H. Itoh, T. Itoh, Variation in molecular species of core lipids from the order Thermoplasmales strains depends on the growth temperature. J. Oleo Sci. 53, 399-404 (2004)

Y. Ueno, K. Yamada, N. Yoshida, S. Maruyama, Y. Isozak, Evidence from fluid inclusions for microbial methanogenesis in the early Archaean era. Nature 440, 516-519 (2006)

H.C. Urey, The origin and development of the Earth and other terrestrial planets. Geochim. Cosmochim. Acta 1, 209-277 (1951)

M.J. Van Kranendonk, Onset of plate tectonics. Science 333, 413-414 (2011)

M.J. Van Kranendonk, A.H. Hickman, R.H. Smithies, I.R. Williams, L. Bagas, T.R. Farrell, Revised Lithostratigraphy of Archaean Supracrustal and Intrusive Rocks in the Northern Pilbara Craton, Western Australia Geol. Surv. West. Austral. Rec., vol. 15 (2006), pp. 1-55

M.J. Van Kranendonk, D. Deamer, T. Djokic, Life springs. Sci. Am. 317, 28-35 (2017)

P. Vannier, G. Michoud, P. Oger, V.T. Marteinsson, M. Jebbar, Genome expression of Thermococcus barophilus and Thermococcus kodakarensis in response to different hydrostatic pressure conditions. Res. Microbiol. 166(9), 717-725 (2015)

A. Ventosa, J.J. Nieto, Biotechnological applications and potentialities of halophilic microorganisms. World J. Microbiol. Biotechnol. 11, 85-94 (1995)

A. Ventosa, A. Oren, Halobacterium salinarum nom. corrig., a name to replace Halobacterium salinarium (Elazari-Volcani) and to include Halobacterium halobium and Halobacterium cutirubrum. Int. J. Syst. Bacteriol. 46, 347 (1996)

A. Ventosa, J.J. Nieto, A. Oren, Biology of moderately halophilic aerobic bacteria. Microbiol. Mol. Biol. Rev. 62, 504-544 (1998)

A. Ventosa, M.C. Márquez, C. Sánchez-Porro, R. Rafael, Taxonomy of halophilic archaea and bacteria, in Advances in Understanding the Biology of Halophilic Microorganisms (Springer, Dordrecht, 2012), pp. 59-80

H.C. Ver Eecke, D.A. Butterfield, J.A. Huber, M.D. Lilley, E.J. Olson, K.K. Roe, L.J. Evans, A.Y. Merkel, H.V. Cantin, J.F. Holden, Hydrogen-limited growth of hyperthermophilic methanogens at deep-sea hydrothermal vents. Proc. Natl. Acad. Sci. USA 109, 13674-13679 (2012) 
H.C. Ver Eecke, N.H. Akerman, J.A. Huber, D.A. Butterfield, J.F. Holden, Growth kinetics and energetics of a deep-sea hyperthermophilic methanogen under varying environmental conditions. Environ. Microbiol. Rep. 5, 665-671 (2013)

A. Vezzi, S. Campanaro, M. D’Angelo, F. Simonato, N. Vitulo, F.M. Lauro, A. Cestaro, G. Malacrida, B. Simionati, N. Cannata, C. Romualdi, D.H. Bartlett, G. Valle, Life at depth: photobacterium profundum genome sequence and expression analysis. Science 307, 1459-1461 (2005)

D.V. von Klein, H. Arab, H. Völker, M. Thomm, Methanosarcina baltica, sp. nov., a novel methanogen isolated from the Gotland Deep of the Baltic Sea. Extremophiles 6, 103-110 (2002)

R.H. Vreeland, Mechanisms of halotolerance in microorganisms. Crit. Rev. Microbiol. 14, 311-356 (1987)

R.H. Vreeland, S. Straight, J. Krammes, K. Dougherty, W.D. Rosenzweig, M. Kamekura, Halosimplex carlsbadense gen. nov., sp. nov., a unique halophilic archaeon, with three 16S rRNA genes, that grows only indefined medium with glycerol and acetate or pyruvate. Extremophiles 6, 445-452 (2002)

D. Wacey, Early life on Earth, a practical guide, in Topics in Geobiology, vol. 31, ed. by N.H. Landman, P.J. Harries (Springer, Heidelberg, 2009)

D. Wagner, J. Schirmack, L. Ganzert, D. Morozova, K. Mangelsdorf, Methanosarcina soligelidi sp. nov., a desiccation- and freeze-thaw-resistant methanogenic archaeon from a Siberian permafrost-affected soil. Int. J. Syst. Evol. Microbiol. 63, 2986-2991 (2013)

M. Wain $\varnothing$, B.J. Tindall, K. Ingvorsen, Halorhabdus utahensis en. nov., sp. nov., an aerobic, extremely halophilic member of the Archaea from Great Salt Lake, Utah. Int. J. Syst. Evol. Microbiol. 50, 183-190 (2000)

J.H. Waite Jr., W.S. Lewis, B.A. Magee, J.I. Lunine, W.B. McKinnon, C.R. Glein, O. Mousis, D.T. Young, T. Brockwell, J. Westlake et al., Liquid water on Enceladus from observations of ammonia and 40Ar in the plume. Nature 460, 487-490 (2009)

J.H. Waite, T. Brockwell, W.S. Lewis, B. Magee, W.B. McKinnon, O. Mousis, A. Bouquet, Enceladus plume composition. LPI Contrib. 1774, 4013 (2014)

J.H. Waite, C.R. Glein, R.S. Perryman, B.D. Teolis, B.A. Magee, G. Miller, J. Grimes, M.E. Perry, K.E. Miller, A. Bouquet, J.I. Lunine, T. Brockwell, S.J. Bolton, Cassini finds molecular hydrogen in the Enceladus plume: evidence for hydrothermal processes. Science 356, 155-159 (2017)

A.E. Walsby, A square bacterium. Nature (London) 283, 69-71 (1980)

M.M. Walsh, Microfossils and possible microfossils from the Early Archean Onverwacht Group, Barberton mountain land, South Africa. Precambrian Res. 54, 271-293 (1992)

M.M. Walsh, D.R. Lowe, Modes of accumulation of carbonaceous matter in the early Archaean: a petrographic and geochemical study of the carbonaceous cherts of the Swaziland Supergroup, in Geologic Evolution of the Barberton Greenstone Belt, South Africa, ed. by D.R. Lowe, G.R. Byerly. Geological Society of America Special Paper, vol. 329, Boulder, CO (1999), pp. 115-132

M.R. Walter, R. Buick, J.S.R. Dunlop, Stromatolites 3400-3500 Myr old from the North Pole area, Western Australia. Nature 284, 443-445 (1980)

C.R. Webster, P.R. Mahaffy, S.K. Atreya, G.J. Flesch, M.A. Mischna, P.Y. Meslin, K.A. Farley, P.G. Conrad, L.E. Christensen, A.A. Pavlov et al., Mars methane detection and variability at Gale crater. Science 347, 415-417 (2015)

F. Westall, M.J. de Wit, J. Dann, S. van der Gaast, C.E.J. de Ronde, D. Gerneke, Early Archean fossil bacteria and biofilms in hydrothermally-influenced sediments from the Barberton greenstone belt, South Africa. Precambrian Res. 106, 93-116 (2001)

F. Westall, S.T. de Vries, J.N. Nijman, D. Marchesini, A. Severine, The 3.446 Ga "Kittys Gap Chert", an early Archean microbial ecosystem, in Processes on the Early, ed. by W.U. Reimold, R.L. Gibson. Earth. Geol. Soc. Amer. Spec. Pap., vol. 405 (2006), pp. 105-131

F. Westall, B. Cavalazzi, L. Lemelle, Y. Marrocchi, J.N. Rouzaud, A. Simionovici, M. Salomé, S. Mostefaoui, C. Andreazza, F. Foucher, J. Toporski, A. Jauss, V. Thiel, G. Southam, L. MacLean, S. Wirick, A. Hofmann, A. Meibom, F. Robert, C. Défarge, Implications of in situ calcification for photosynthesis in a $~ 3.3$ Ga-old microbial biofilm from the Barberton Greenstone Belt, South Africa. Earth Planet. Sci. Lett. 310, 468-479 (2011)

F. Westall, K. Hickman-Lewis, N. Hinman, P. Gautret, K.A. Campbell, J.G. Bréhéret, F. Foucher, A. Hubert, S. Sorieul, A.V. Dass, T.P. Kee, T. Georgelin, A. Brack, A hydrothermal-sedimentary context for the origin of life. Astrobiology 18, 259-293 (2018)

M.J. Whitehouse, D.J. Dunkley, M.A. Kusiak, S.A. Wilde, On the true antiquity of Eoarchean chemofossilsassessing the claim for Earth's oldest biogenic graphite in the Saglek Block of Labrador. Precambrian Res. 323, 70-81 (2019)

W.B. Whitman, D.C. Coleman, W.J. Wiebe, Prokaryotes: the unseen majority. Proc. Natl. Acad. Sci. USA 95, 6578-6583 (1998)

R.J.P. Williams, J.J.R. Fraústo Da Silva, Evolution was chemically constrained. J. Theor. Biol. 220, 323-343 (2003) 
«SPAC 11214 layout: Small Condensed v.2.1 file: spac620.tex (ikurtinaitiene) class: spr-small-v1.4 v.2019/10/07 Prn:2019/12/05; 11:32 p. 42/42» doctopic: ReviewPaper numbering style: ContentOnly reference style: aps»

R. Winter, Effect of lipid chain length, temperature, pressure and composition on the lateral organisation and phase behavior of lipid bilayer/gramicidin mixtures. Biophys. J. 82, 153A-153A (2002)

R. Winter, C. Jeworrek, Effect of pressure on membranes. Soft Matter 5, 3157-3173 (2009)

C.R.A. Woese, Proposal concerning the origin of life on the planet Earth. J. Mol. Evol. 13, 95-101 (1979)

J.M. Wood, E. Bremer, L.N. Csonka, R. Krämer, B. Poolman, T. van der Heide, L.T. Smith, Osmosensing and osmoregulatory compatible solute accumulation by bacteria. Comp. Biochem. Physiol., Part A 130, 437-460 (2001)

Y. Xu, P. Zhou, X. Tian, Characterization of two novel haloalkaliphilic archaea Natronorubrum bangense gen. nov., sp.nov., and Natronorubrum tibetense gen. nov., sp. nov. Int. J. Syst. Bacteriol. 49, 261-266 (1999)

K. Yamauchi, K. Doi, Y. Yoshida, M. Kinoshita, Archaebacterial lipids: highly proton-impermeable membranes from 1, 2-diphytanyl-sn-glycero-3-phosphocholine. Biochim. Biophys. Acta 1146, 178-182 (1993)

P.H. Yancey, Organic osmolytes as compatible, metabolic and counteracting cytoprotectants in high osmolarity and other stresses. J. Exp. Biol. 208, 2819-2830 (2005)

Y. Yano, A. Nakayama, K. Ishihara, H. Saito, Adaptive changes in membrane lipids of barophilic bacteria in response to changes in growth pressure. Appl. Environ. Microbiol. 64, 479-485 (1998)

A.A. Yayanos, A.S. Dietz, R. Van Boxtel, Obligately barophilic bacterium from the Mariana trench. Proc. Natl. Acad. Sci. USA 78(8), 5212-5215 (1981)

J. Zajc, P. Zalar, N. Gunde-Cimerman, Yeasts in hypersaline habitats, in Yeasts in Natural Ecosystems: Diversity (Springer, Cham, 2017), pp. 293-329

X. Zeng, J.L. Birrien, Y. Fouquet, G. Cherkashov, M. Jebbar, J. Querellou, P. Oger, M.A. Cambon-Bonavita, X. Xiao, D. Prieur, Pyrococcus $\mathrm{CH} 1$, an obligate piezophilic hyperthermophile: extending the upper pressure-temperature limits for life. ISME J. 3, 873-876 (2009)

G. Zhang, N. Jiang, X. Liu, X. Dong, Methanogenesis from Methanol at Low Temperatures by a Novel Psychrophilic Methanogen, "Methanolobus psychrophilus" sp. nov., Prevalent in Zoige Wetland of the Tibetan Plateau. Appl. Environ. Microbiol. 74, 6114-6120 (2008)

T.N. Zhilina, G.A. Zavarzin, Methanohalobium evestigatus, n. gen., n. sp. The extremely halophilic methanogenic Archaebacterium. Dokl. Akad. Nauk SSSR, vol. 293 (1987), pp. 464-468

T.N. Zhilina, D.G. Zavarzina, V.V. Kevbrin, T.V. Kolganova, Methanocalculus natronophilus sp. nov., a new alkaliphilic hydrogenotrophic methanogenic archaeon from a soda lake, and proposal of the new family Methanocalculaceae. Microbiology 82, 698-706 (2013)

L. Zhou, X. Liu, X. Dong, Methanospirillum psychrodurum sp. nov., isolated from wetland soil. Int. J. Syst. Evol. Microbiol. 64, 638-641 (2014)

C.E. Zobell, F.H. Johnson, The influence of hydrostatic pressure on the growth and viability of terrestrial and marine bacteria. J. Bacteriol. 57, 179-189 (1949)

M.Y. Zolotov, J.S. Kargel, On the chemical composition of Europa's icy shell, ocean, and underlying rocks, in Europa, ed. by R.T. Pappalardo, W.B. McKinnon, K.K. Khurana. The University of Arizona Space Science Series (University of Arizona Press, Tucson, 2009), p. 431 